\title{
Galerías de agua en el campo alto de Lorca (Región de Murcia). Análisis y caracterización territorial
}

\author{
Water galleries in the high field of Lorca (Region of Murcia). \\ Analysis and territorial characterisation
}

\author{
José Antonio López Fernández ${ }^{1} \mathbb{D}$
}

\section{Resumen}

En este trabajo se analizan los principales sistemas tradicionales de acopio de agua localizados en el campo alto de Lorca. Ingenios de captación del tipo galería drenante o qanat, cuyos recursos se han destinado para usos locales de estas pedanías, tanto para abastecimiento de boca como regadío. Sin embargo, el caudal de algunos afloramientos permitió que, durante siglos, parte de sus aguas se destinaran a abastecer a la población de la capital, por medio de kilométricas redes de distribución. El trabajo de campo y la documentación de archivo han sido esenciales en esta investigación, donde se pone de manifiesto el esfuerzo secular de comunidades asentadas en un territorio de clima semiárido y escasos recursos superficiales. Los resultados muestran la existencia de numerosas galerías de agua, con elementos y funciones similares a otros ejemplos del Sureste de España, aunque con factores espaciales e históricos singulares. No es posible entender la configuración de este paisaje rural si no se conoce la influencia territorial que, a lo largo del tiempo, han jugado los sistemas de galerías horizontales; construcciones que, en muchos casos, siguen funcionales, conservadas y mantenidas por la población local.

Palabras clave: Galerías de agua; galerías con lumbreras; qanat; patrimonio hidráulico; medio rural; campo alto de Lorca; Región de Murcia.

\begin{abstract}
In this dissertation, the main traditional water collection systems located in the highlands of Lorca are analysed. Catchment mills of a draining gallery or qanat type were used for local drinking and irrigation supply. However, for centuries the flow of some outcrops enabled part of the waters to be used to supply the population in the capital - using kilometres of distribution networks. Fieldwork and archival documentation have been essential in this investigation, which highlights the effort of communities settled in a semi-arid territory with limited surface resources. The results show the existence of numerous water galleries, with elements and functions similar to other examples in the southeast of Spain, although with unique spatial and historical factors. It is not possible to understand the configuration of this rural landscape without considering the territorial influence played by these horizontal gallery systems. In many cases, these constructions remain functional and maintained by the local population.
\end{abstract}

Keywords: Water galleries; galleries with louvres; qanat; hydraulic heritage; rural environment; high fields of Lorca; Murcia region.

1 Departamento de Didáctica de las Ciencias Sociales y Experimentales, Universidad de Córdoba, España. jalopez@uco.es 


\section{Introducción}

En las pedanías altas de Lorca, en el interior de la Región de Murcia —al sureste de la Península Ibérica- existen numerosos ingenios tradicionales destinados a la captación de aguas subálveas; un territorio caracterizado por un clima semiárido (Figura 1). El segundo municipio más extenso de España destaca por la inexistencia de cursos fluviales de carácter permanente por lo que, históricamente, el abastecimiento de personas, de ganado y la necesidad de disponer de agua para el regadío debió realizarse a través de caudales subterráneos, lo que se tradujo en el desarrollo de galerías horizontales, cuyo aprovechamiento trasciende del ámbito local.

Figura 1. Localización del área de estudio. Campo Alto de Lorca (Región de Murcia)

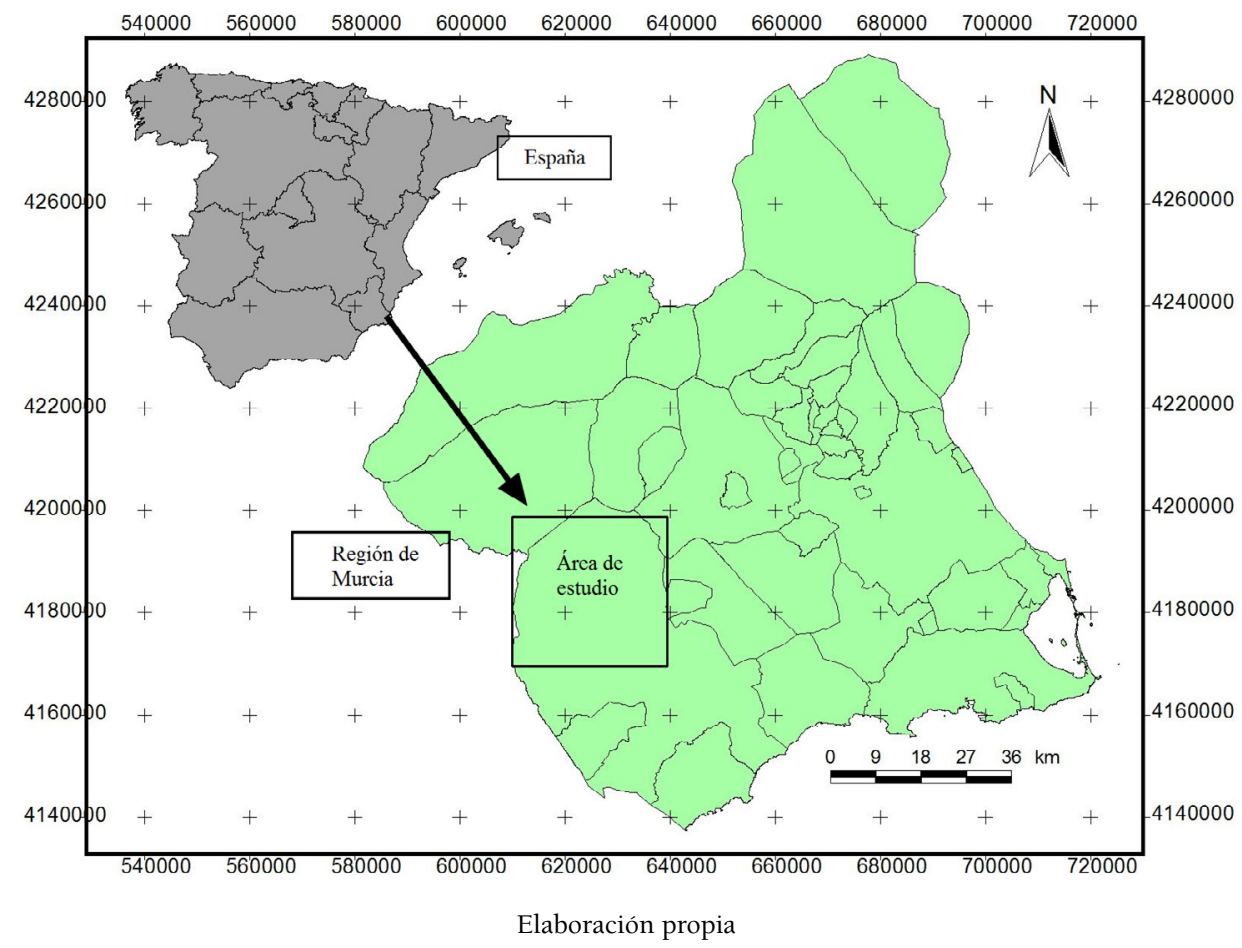

Se trata de ingenios hidráulicos de carácter patrimonial (Iranzo, Antequera y Hermosilla, 2010; Gómez y Hervás, 2012; Castejón y Canales, 2016; Luna, García y Luján, 2006) que han sido vitales para el desarrollo de los pueblos aquí asentados, además de constituir elementos clave en la configuración del territorio actual. En el sureste de España, destacan los estudios realizados por Gil y Gómez (1993), que señalan el término de galerías con lumbreras para designar los pozos horizontales destinados a la captación tradicional de agua en la Región de Murcia. Estas construcciones, no obstante, han sido examinadas en otros territorios (Barceló, 1983; Gea, 1990; Hermosilla, 2006; Llamas, 1976; Martínez y Ruano, 1998; Palerm, 2004; Pavón, 1990; Pocklington, 1988; Roth y Schütz, 2001; Trol y Braun, 1974; Barón y Carbonero, 1987; o Vidal, 1989; entre otros). Un término, el de galerías con lumbreras, que puede ser sinónimo del planteado recientemente por Antequera (2015), el de galerías drenantes.

Podemos señalar que una galería drenante o galería con lumbreras es lo que, en otros territorios, recibe el nombre de qanat-s, foggara-s, kettara-s, alcavos, viajes de agua o minados con espejuelos, topónimo éste último utilizado históricamente en la comarca del Altiplano murciano. Grosso modo, se trata de una mina subterránea cuasi horizontal, con escasa pendiente, que arranca en un pozo madre, de donde se obtiene o capta el agua del subsuelo o freático próximo, en el contacto entre una capa permeable y otra subyacente impermeable. A partir de este lugar, se traza el recorrido de la mina que, a lo largo de su trayecto, va a presentar uno o varios pozos verticales - lumbreras-, construidos con la finalidad de extraer los acarreos en la primigenia obra o los que van a proceder de las necesarias tareas de limpieza, así como proporcionar ventilación al sistema. Sin embargo, la morfología de este tipo de sistemas puede complicarse debido a las características ambientales de cada espacio, con la presencia, por ejemplo, de galerías secundarias o transversales a la general con el fin de buscar varios puntos de captación de agua, entradas horizontales, 
materiales disponibles, lucernarios para alojar velas o candiles, etc. Esta complejidad hace que, en la comunidad de especialistas, existan diferentes interpretaciones sobre la consideración de las particularidades de una galería o qanat, diferenciándolas de otro tipo de ingenios hidráulicos de parecidas características.

\subsection{Hipótesis y objetivos del trabajo}

La hipótesis de partida reside en la existencia de numerosos sistemas de galerías drenantes repartidos por el campo alto de Lorca, con la notoria entidad territorial e histórica para ser considerados como uno de los ingenios hidráulicos tradicionales más importantes de este término, que dan sentido al paisaje actual. Junto a ello, elementos anexos como balsas, canales de conducción, lavaderos o pilones que forman parte del legado cultural de este espacio. A través de la investigación en campo y el análisis de documentación de archivo, intentamos evidenciar la importancia de estos aprovechamientos históricos y la relevancia actual que estos sistemas tuvieron, y tienen, en el desarrollo de la población de este territorio.

Por medio de los datos obtenidos, pretendemos comprender la magnitud de estas infraestructuras para proveer de agua, no solo a los cultivos locales de las pedanías altas, sino a las huertas que se van a expandir alrededor de Lorca, en el valle del Guadalentín. Ahora bien, hay que tener en cuenta que el regadío lorquino constituye un caso paradigmático que, como en el de Alicante, va a presentar desde hace varios siglos la propiedad de las aguas separada de la tierra; ejemplo que se expandiría a gran parte de los espacios de riego deficitario del sureste peninsular (Gil, 1993). Esta situación, en un contexto geográfico de escasez hídrica, daría lugar a proyectos de gran magnitud, algunos tan inverosímiles que ponen de manifiesto la imperiosa necesidad en la búsqueda de caudales y, por lo tanto, un factor que puede explicar el desarrollo de los sistemas tradicionales de captación de aguas. De este modo, las clases más pudientes por un lado y, sobre todo, la unión de pequeños agricultores por otro, tuvieron que realizar grandes esfuerzos económicos y personales para obtener las aguas de las tierras altas del municipio, por medio de minas y galerías de captación subterráneas; en un territorio exiguo en recursos superficiales y con clima mediterráneo semiárido.

Para este estudio nos proponemos, por tanto, la consecución de varios objetivos: a) catalogar y categorizar la tipología de estos aprovechamientos, de acuerdo a la investigación actual; b) analizar los espacios configurados por los sistemas de galerías con lumbreras localizados en el territorio del campo alto de Lorca y su influencia histórica en la capital municipal; c) determinar la relación entre el aprovechamiento de los recursos hídricos y el desarrollo de la población y el poblamiento existente en las pedanías altas de Lorca.

\subsection{Estado de la cuestión sobre las galerías drenantes}

La capacidad del ser humano para extraer agua del subsuelo ha sido bastante limitada hasta bien entrado el siglo XX. No será hasta los años 60 y 70 cuando los sondeos verticales van a permitir acceder a grandes profundidades. Sin embargo, sí existían conocimientos que, según algunos autores, fundamentan las características mineras de estos complejos hidráulicos (Goblot, 1979), los cuales tendrán un amplio desarrollo en las tierras del Próximo Oriente, en casi todas las regiones del Sahara, en la antigua Persia, el oeste de China o centro y sur de América. Y es que, sobre el funcionamiento de estos sistemas, tuvo lugar el crecimiento de los antiguos pueblos que habitaban territorios con escasas precipitaciones (Al Karaimeh, 2019). En la actualidad, estos sistemas de captación de aguas subálveas son fundamentales en países como Irán, donde se estima la presencia de más de 37.000 galerías, que aportan el $11 \%$ de todos los recursos hídricos disponibles (Megdiche-Kharrat, Ragala y Moussa, 2019). En países balcánicos y asiáticos, los sistemas de galerías han sido esenciales para el desarrollo de diferentes civilizaciones.

Some researchers reported that the first water well of Iran was dug simultaneously with the first

Qanat. There are hand dug water wells still in use today in parts of the Persian Empire which were constructed more than 3,000 years ago. (Voudouris et al., 2019, p. 362)

Pérez (2005) señala la presencia de galerías y minas como un elemento esencial para aprovechar los caudales subterráneos en el ámbito mediterráneo, tanto en España como en el norte de África (Fansa, Antequera y Hermosilla, 2017); infraestructuras destinadas tanto para el abastecimiento de personas como para el regadío. Una técnica de construcción que se remonta a épocas romana y árabe, caso del qanat de Ocaña en Toledo (López-Camacho, Bustamante e Iglesias, 2005). Las galerías con lumbreras, como señala Murcia (1958) es una técnica hidráulica, desarrollada en lugares áridos y semiáridos, con una amplia presencia en el ámbito español (López-Camacho, 2001; López-Camacho et al. 2005). 
La población de Lorca ha estado secularmente marcada por la necesidad de abastecimiento hídrico. La escasez de recursos propios determina la búsqueda histórica de agua en otros territorios alejados de la capital, como los de la fuente de Tirieza en el siglo VIII, según documentos de Al-Himyari (Roth y Shütt, 2001) y los manantiales de Ojos de Luchena y Zarzadilla de Totana (Madoz, 1850), al norte del término. Incluso también existió la intención de conducir los caudales de los ríos Castril y Guardal, así como las Fuentes del Marqués de Caravaca. En el siglo XX, el ingeniero Ángel Elul (1929-1932), al describir el territorio de las pedanías altas, identifica algunos aprovechamientos realizados por medio de galerías con lumbreras (Pelegrín, 2010). Otro investigador, en este caso el historiador y cronista lorquino Joaquín Espín Rael, recogió interesante información sobre los Ojos de Luchena; documentación no publicada, alojada en el Archivo Municipal de Lorca. Pelegrín (2006) describe cuatro obras hidráulicas de carácter histórico en Lorca, entre las que se encuentra el acueducto de Zarzadilla de Totana, construido para conducir las aguas de la galería de esta población a la capital lorquina. García y Pelegrín (2002) analizan las características y los caudales históricos del manantial de Ojos de Luchena. Nacimiento de agua que también fue evaluado ampliamente por Rodríguez (1995). Por su parte, López (2015) presta atención a la funcionalidad del sistema local de galería drenante La Mina, situado por encima de la población de Zarcilla de Ramos.

Por el contrario, no se ha realizado un análisis geográfico general de este tipo de aprovechamientos, ni su influencia en el desarrollo de las entidades locales de carácter rural así como de la capital lorquina. A tenor de las investigaciones en campo y de otras experiencias previas, no resulta fácil realizar una clasificación de estos sistemas, así como determinar si su origen responde a técnicas mineras. Otras investigaciones también han puesto de manifiesto esta compleja tarea, debido a la amplia diversidad de sistemas de captación subterránea encontrados en el ámbito de la cuenca mediterránea (López-Camacho, 2001; Hermosilla, 2008; Antequera, Iranzo y Hermosilla, 2014). Respecto al origen de esta técnica constructiva, Hermosilla, Iranzo, Pérez, Antequera y Pascual (2004) recogen la tesis presentada por Goblot (1979), que indica que las galerías de agua responden a una construcción que requiere conocimientos mineros. Por su parte, Barceló (1986) entiende que la búsqueda del agua se puede realizar por medio de zanjas que, posteriormente, pueden ser recubiertas y, por lo tanto, no es necesario conocer técnicas mineras para su construcción. En este mismo sentido, Barceló (1986) indica que estos sistemas responden a las necesidades locales de cada espacio, por lo que los constructores van a actuar de acuerdo a sus posibilidades técnicas, con la finalidad de obtener caudales que amorticen la construcción de la obra. De acuerdo con la definición anterior, intentar clasificar las galerías con lumbreras resulta complejo por multitud de factores. Al respecto, Hermosilla refleja esta complejidad de los sistemas, que "presentan condiciones específicas dependiendo de las características geográficas de un área determinada. Estas adaptaciones se reflejan en una variedad tipológica representativa manifestada por las técnicas de construcción de las galerías y por las diferencias morfológicas de estas". (2008, p. 22)

En un trabajo bastante interesante y poco referenciado, Murcia (1958) señala que, según convenga, pueden darse las siguientes construcciones: Trincheras colectoras, a modo de zanjas subterráneas. Galerías filtrantes, refiriéndose a minas que tienen el fin de aprovechar las aguas subálveas de valles fluviales. Galerías de captación, que es "propiamente el socavón” (Murcia, 1958, p. 158). Autores como Ron (1996) o Martí (1989), por su parte, advierten de las diferencias que existen entre una mina de agua y un qanat o galería, siendo esta última la que se desarrolla a partir de un pozo madre, que da agua tras su construcción y requiere la cimentación de una galería horizontal para conducir el caudal de la captación a cielo abierto. Gil y Gómez (1993), Gómez (2004a) o Gómez, Gil, Aliaga, López y Martínez (2007), diferencian estas construcciones entre sistemas de galerías filtrantes y drenantes. Las primeras, realizadas bajo depósitos de gravas en ríos-ramblas; las segundas, por su parte, construidas bajo depósitos aluviales y coluviales en áreas sedimentarias como glacis y piedemontes. Hermosilla et al. (2004) diferencian entre galerías situadas en áreas de montaña, donde aparecen minas y galerías con o sin pozo madre; galerías en áreas intermedias o piedemontes, espacios donde se encuentran los qanawat (qanat en plural) propiamente dichos; galerías en cursos y terrazas fluviales, con la construcción de cimbras y zanjas, con lumbreras tanto verticales como horizontales (Hermosilla, 2008) para extraer los caudales subálveos.

\section{Metodología}

\subsection{Procedimientos metodológicos de la investigación}

La metodología de esta investigación se articula en base a cuatro fuentes de información: el trabajo de campo, realizado durante la segunda mitad del año 2019, para analizar in situ las características 
constructivas y morfológicas de las galerías, el análisis de la bibliografía relacionada con los sistemas drenantes (de ámbito local, de carácter geográfico, histórico o etnográfico, así como de síntesis), el estudio de documentación histórica existente en el Archivo Municipal de Lorca y el uso de imágenes aéreas, actuales y pasadas, tratadas a partir de fotointerpretación y sistemas de información geográfica. Paralelamente, las fases del trabajo también son cuatro, complementarias e interrelacionadas, y que se han seguido en otros estudios, aunque con algunas diferencias (Hermosilla et al., 2004; 2008; Hermosilla, Antequera e Iranzo, 2012; Gil y Gómez, 2007; Gil, 2009).

Figura 2. Fases de trabajo implementadas en la investigación

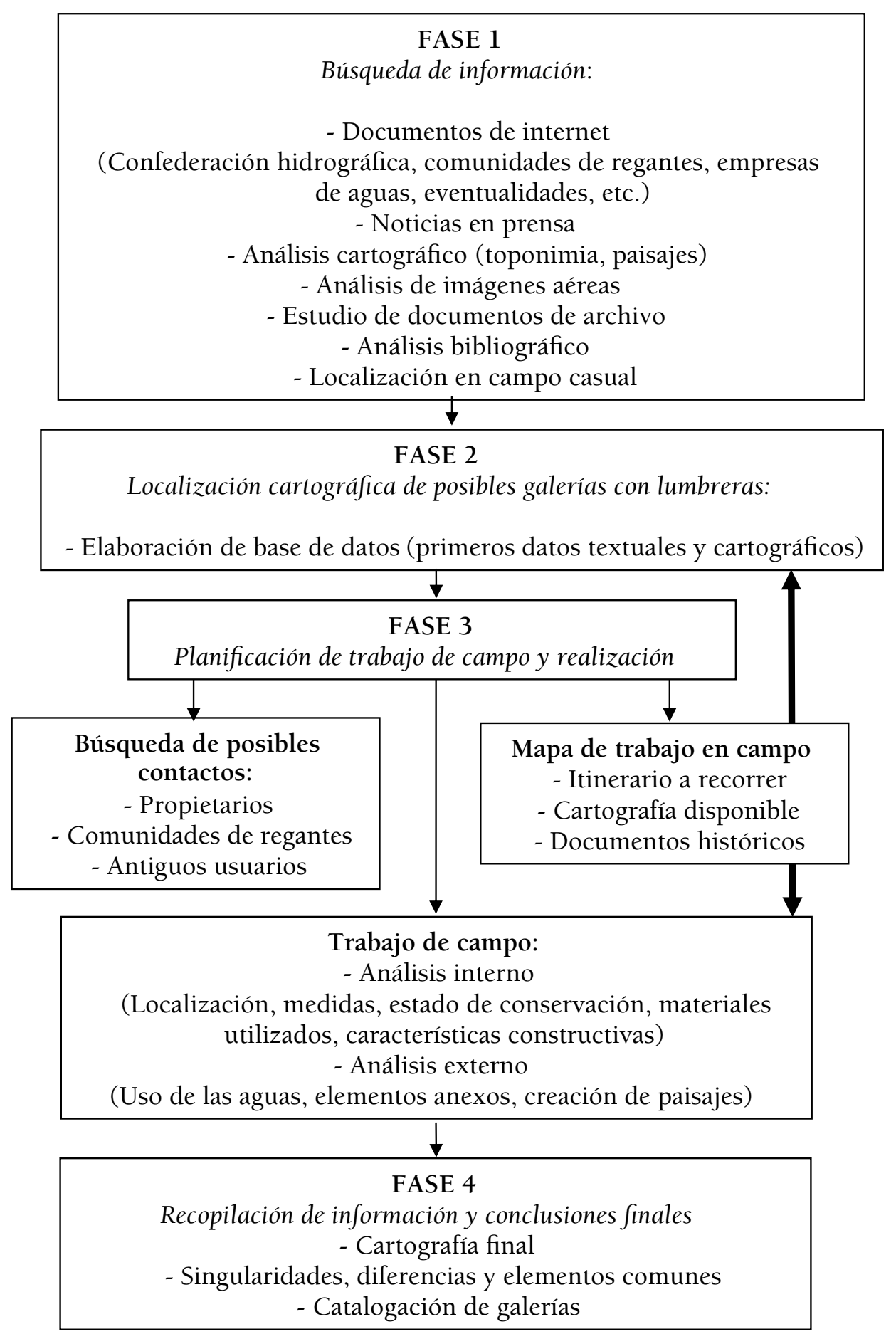

Elaboración propia 
De este modo, para el análisis de los sistemas hidráulicos de captación de aguas del campo alto de Lorca, hemos implementado la estructura de trabajo recogida en la Figura 2. La primera fase, articulada en base al objetivo principal del trabajo, comienza con la búsqueda de información sobre puntos de agua repartidos por el territorio objeto de estudio. Esta indagación se realiza de forma estructurada según la consulta de diferentes fuentes documentales y cartográficas, y también por medio de unas primeras jornadas de campo, con la visita in situ a fuentes y manantiales. A partir de aquí, se crea una base de datos con información georreferenciada, que servirá de punto de partida para la fase 3 .

Esta se estructura en torno a la planificación y realización del trabajo de campo, con la visita a los sistemas drenantes y la concertación de entrevistas con expertos y conocedores del territorio. En esta fase también se comprueban las situaciones descritas en documentos históricos y se comparan con el estado actual de las diferentes captaciones. Se analizan las características constructivas de las galerías, su estado de conservación y funcionalidad, así como su papel en la configuración de paisajes locales y su valor patrimonial, a través del estudio de otros posibles elementos anexos, que permiten diversificar el uso del agua, diferente al regadío. La fase final se corresponde con el análisis global de los sistemas encontrados y su influencia en el territorio, se catalogan en base a sus características y se elabora una cartografía final.

Todas las fases son necesarias para una correcta identificación y estudio de estos sistemas. En este caso, el trabajo de campo y análisis geográfico es fundamental en este tipo de estudios, sobre todo al considerar que cada sistema presenta sus rasgos identitarios conforme a su situación espacial y desarrollo histórico. De gran importancia es la indagación por medio de antiguas imágenes aéreas con visores informáticos y geoportales, que permiten identificar las hileras de lumbreras y espacios regados, complementados con la información de archivo, lo que facilita el posterior trabajo de campo. En nuestro caso, el estudio de documentos en el Archivo Municipal de Lorca y algunos trabajos bibliográficos, referentes a la construcción de estos sistemas y el control de los caudales aforados, permiten disponer de interesante información histórica, que complementa a los estudios geográficos actuales.

Nuestro enfoque metodológico también descansa en los postulados de la geografía cultural (Ortega, 2000); una rama de la geografía humana, que intenta analizar y explicar la relación histórica entre el ser humano y su entorno, que tiene, como resultado, una producción cultural, tanto de carácter material como inmaterial. En este sentido, se intenta realizar, no solo un análisis minucioso de cada galería drenante, sino del conjunto de elementos que componen cada sistema, desde la captación a la distribución del agua así como los diferentes usos otorgados a este escaso bien natural. Este compendio de información se analiza para intentar ofrecer una síntesis territorial, en cuanto al uso del agua, en un espacio, marcado por la relación histórica de la sociedad y el esfuerzo de esta por conseguir un recurso tan necesario como escaso. Se intenta, con esta metodología, poner de manifiesto la forma de vida de una población que ha desarrollado una cultura hídrica e hidráulica, que se ha adaptado a vivir en un territorio de características semiáridas, y que se evidencia por medio de sus paisajes (Hermosilla e Iranzo, 2014).

El paisaje resultante es, por tanto, y ante todo, el fruto de costosísimos esfuerzos del agricultor que con su trabajo y un rudimentario instrumental, ha modelado laderas y cauces hasta límites insospechados, "el campo es aquí, sobre todo, arquitectura" (Deffontaines, 1972). Una transformación, en definitiva, que implica no solo un trabajo penoso, sino lo que es más de encarecer, interminable (...). (Hernández y Morales, 2013, p. 117)

\subsection{Características del espacio de estudio}

El territorio de estudio se localiza en la zona norte del término municipal de Lorca, estructurado por la red hidrográfica del Turrilla. Aquí se encuentran las diputaciones de Avilés, Coy, Doña Inés, La Paca, Zarzadilla de Totana y Zarcilla de Ramos, sector centro-occidental de la Región de Murcia. Por el Norte, las sierras de Campo Coy y las alineaciones de Almirez y de la Pinosa, que se continúan por el noreste con las de Labia y Burete, separan esta zona de las tierras de Caravaca, drenadas de suroeste a noreste por el río-rambla del Quipar. Por su parte, en la zona sur, la cuenca está separada de la depresión del Guadalentín por los relieves de La Tercia y La Torrecilla, de dirección predominante SW-NE. El paso natural entre ambos espacios se produce por una falla NW-SE.

Se trata de una cuenca relativamente alta, alrededor de los 500 metros sobre el nivel del mar, que presenta una red de drenaje de carácter temporal, cuando tienen lugar intensas precipitaciones concentradas en reducidos periodos de tiempo. Esta cubeta de sedimentación tiene, a su vez, relieves interiores que siguen la estructura predominante de las Sierras Béticas, con picos que superan los 1.000 metros de 
altitud. Estas unidades están formadas principalmente por materiales calizos levantados en el Terciario, suprayacentes a paquetes inferiores de carácter impermeable, mayoritariamente margosos; características que justifican la búsqueda histórica de recursos hídricos en el subsuelo de estas tierras.

Figura 3. Paisaje tradicional de las pedanías altas de Lorca. En este caso, Paraje de La Cañada, configurado por extensos valles ocupados por cultivos de secano y jalonados por elevaciones montañosas cubiertas de pinares

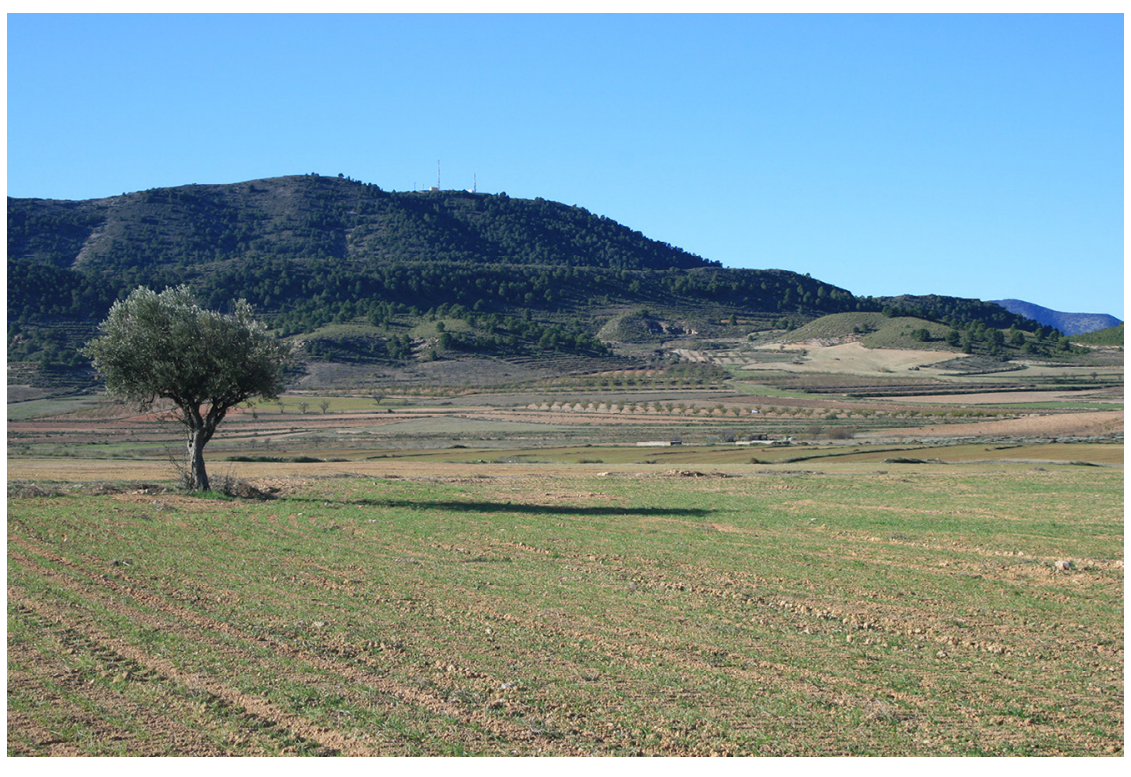

Fotografía del autor

El paisaje típico que ofrece este espacio es el secano mediterráneo, donde se entremezclan los cultivos de cereal, vid, almendros y olivos, regados algunos de ellos con aguas de pozos profundos (Figura 3). Estos cultivos se localizan en cañadas y planicies coluviales, lugares más apropiados para la agricultura y donde existe una mayor disponibilidad de recursos hídricos subterráneos. Junto a ello, también se pueden encontrar ejemplos de cultivo en terrazas a orillas de ramblas y fondos de valle. Alrededor de los núcleos de población, se conservan pequeñas huertas, que han servido históricamente para el abastecimiento de la población local, regadas secularmente con el agua de fuentes y manantiales, como ocurre en Coy y Doña Inés. Los relieves circundantes, por su parte, muestran grandes extensiones de eriales y pinares, estos últimos fruto de repoblaciones en épocas pasadas.

Las precipitaciones que acontecen en este sector son irregulares, intra e interanualmente, concentradas en primavera y otoño. No son frecuentes durante el invierno y rara vez se producen durante el periodo estival. Cuando aparecen lluvias, que suelen ser de tipo orográfico, estas se generan como consecuencia de la llegada de masas de aire del Mediterráneo, obligadas a un ascenso rápido determinado por el relieve. A lo largo de los años también se producen irregularidades relevantes, como en 2005 donde solamente se registraron 173,3 1/m² en la estación meteorológica de La Paca; 471 l/m² en 2006 o 235,17 en 2017. Se trata, pues, de un entorno cuya media anual apenas supera los $300 \mathrm{~mm}$, donde no existen cursos continuos de agua que permitan un aprovechamiento agrícola sostenido por regadío, cuestión que se debió afrontar por medio de la búsqueda de aguas subterráneas.

En cuanto a las temperaturas, los valores muestran un verano con medias de $25^{\circ} \mathrm{C}$ e inviernos que oscilan entre 10 y $12^{\circ} \mathrm{C}$, si bien este espacio, por la configuración del relieve y el relativo efecto de la continentalidad, la media anual es inferior con respecto al resto del territorio municipal. Así, el carácter interior de esta zona muestra amplitudes térmicas por encima de $17-18^{\circ} \mathrm{C}$. Como consecuencia, el déficit hídrico asciende hasta superar los $800 \mathrm{~mm}$, haciendo de las escasas aguas disponibles, un recurso importantísimo para el desarrollo humano.

\section{Resultados}

Los resultados se presentan en dos fases: por un lado, se dispone la información de forma conjunta, analizando características y singularidades de los diferentes aprovechamientos hidráulicos; por otro, se 
ha procedido a realizar una distinción entre los complejos de galerías que tienen un aprovechamiento local y aquellos que, a lo largo de los últimos siglos se han acomodado para abastecer a la población de la capital lorquina, como son los sistemas de Zarzadilla de Totana y Ojos de Luchena.

Respecto a la localización espacial del conjunto de sistemas drenantes, puede comprobarse según la Figura 4 una amplia distribución en el campo alto de Lorca, relativamente cercanos a los núcleos de población y que han funcionado como fuentes de abastecimiento secular para proveer de agua a lavaderos y abrevaderos pero, sobre todo, para la toma de boca y el regadío.

En este sentido, puede entenderse que el germen del actual poblamiento está condicionado por la primitiva localización de alquerías y ventas, que se levantaron en cruces de caminos entre veredas y cañadas, a su vez determinados por la disposición de abrevaderos con origen en fuentes y manantiales naturales. Con toda probabilidad, posteriormente se acometieron obras para incrementar las aguas disponibles, según se desprende de la documentación de archivo, sobre todo en los de mayor caudal como en Ojos de Luchena. El ejemplo de esta galería va a constituir un punto de interés, no solo a nivel local, sino para el desarrollo de la capital lorquina y su huerta, al aportar durante siglos caudales continuos que permiten poner en regadío parte del valle del Guadalentín (Gil, 1993).

Figura 4. Sistemas de galerías drenantes analizados en las Pedanías Altas de Lorca

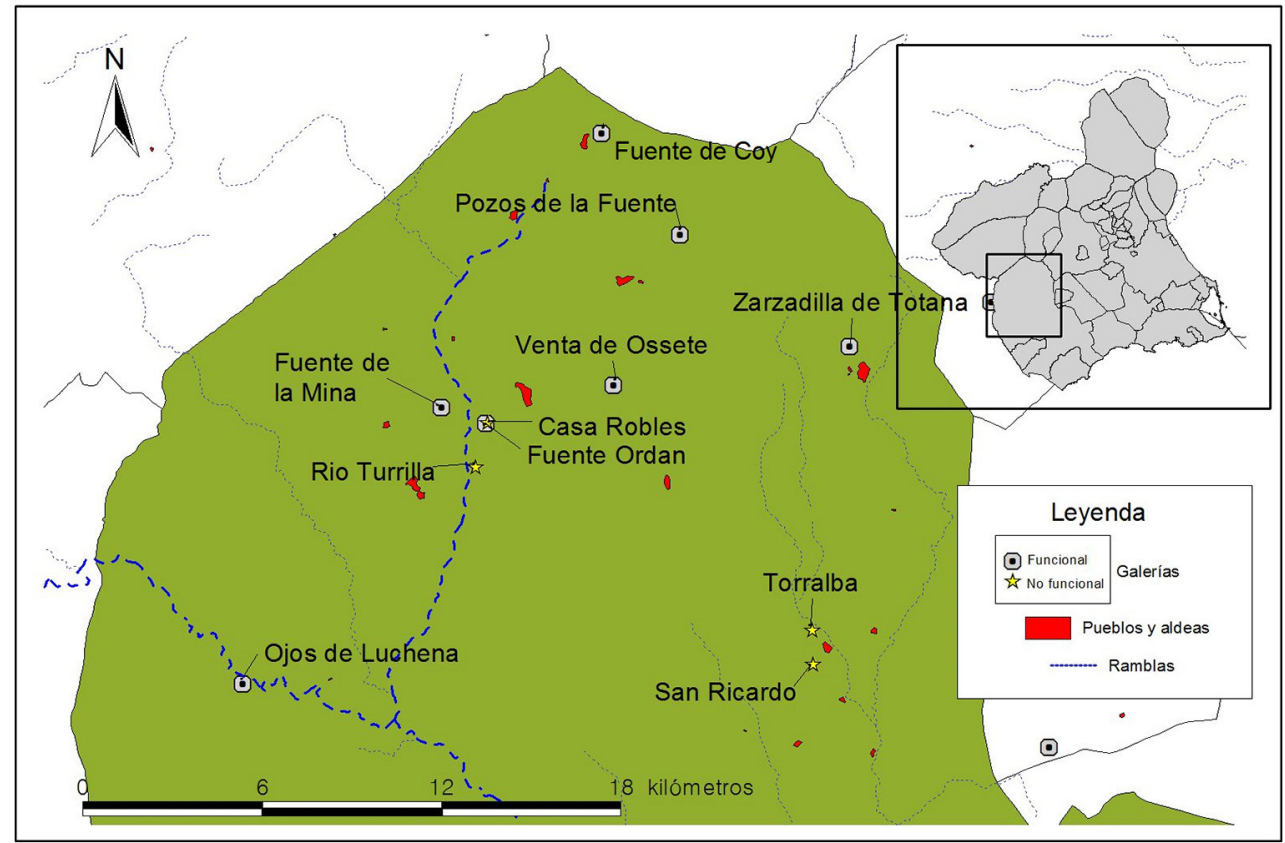

Elaboración propia

En la Tabla 1 se recogen las principales características morfológicas y funcionales de los sistemas de galerías encontrados en las pedanías altas de Lorca. Se destacan las que están operativas en la actualidad, la tipología de construcción, los materiales utilizados para su edificación y los elementos anexos que permiten el uso del agua. Además, se incluye información relacionada con la distancia de los sistemas y el aporte de caudal, aunque este último es muy variable a lo largo de los años.

En conjunto, podemos advertir que, en la actualidad, estos ingenios siguen siendo importantes, sobre todo para ayudar a conservar regadíos tradicionales, como el existente alrededor de la villa de Avilés, o por medio de la fuente de La Mina, al norte de Zarcilla de Ramos, que ayuda al funcionamiento de una comunidad de regantes. De las once construcciones inventariadas, siete se conservan funcionales, con evidencias recientes de obras de mantenimiento en algunos sistemas como es el caso de la Finca de Ossete, donde se ha procedido a restaurar los brocales de las lumbreras (Figura 5).

En cuanto a la localización, cinco de estos sistemas se construyeron en piedemontes o glacis, cuatro aprovechando los subálveos de lechos y terrazas fluviales y dos ocuparon espacios de valle, con la finalidad de captar aguas subálveas. Respecto a la tipología de estos sistemas, seis podemos considerarlos como 
ejemplos de galerías con lumbreras o galerías drenantes, otros dos son cimbras o galerías de filtración de agua, situadas bajo lechos fluviales (Pozos de la Fuente y Ojos de Luchena) y una constituye un sistema de zanjas o minados con lumbreras, fundamentalmente de conducción como es el complejo del margen izquierdo del río Turrilla. La fuente de Coy, por su parte, constituye un aprovechamiento del tipo zanja sin lumbreras, recogiendo las aguas entre dos capas geológicas.

Tabla 1. Características constructivas y morfológicas de las galerías drenantes estudiadas en el Campo Alto de Lorca

\begin{tabular}{|c|c|c|c|c|c|c|c|}
\hline Nombre & $\begin{array}{l}\text { Estado } \\
\text { F/Nf }\end{array}$ & $\begin{array}{l}\text { Ámbito } \\
\text { geomorf. }\end{array}$ & Tipología & $\begin{array}{l}\text { Elementos } \\
\text { constructivos }\end{array}$ & $\begin{array}{l}\text { Elementos } \\
\text { anexos y usos }\end{array}$ & \multicolumn{2}{|c|}{$\begin{array}{l}\text { Distancia }(\mathrm{m}) \\
\text { y caudal }(1 / \mathrm{s})\end{array}$} \\
\hline $\begin{array}{l}\text { Zarzadilla de } \\
\text { Totana }\end{array}$ & F & Piedemonte & $\begin{array}{l}\text { Qanat con } \\
\text { lumbreras }\end{array}$ & Revestida en piedra & $\begin{array}{l}\text { Depósito, lavadero, } \\
\text { balsa, acueductos }\end{array}$ & 190 & 3 \\
\hline $\begin{array}{l}\text { Pozos de la } \\
\text { Fuente }\end{array}$ & F & $\begin{array}{l}\text { Lecho fluvial } \\
\text { de rambla }\end{array}$ & $\begin{array}{l}\text { Cimbra con } \\
\text { lumbreras }\end{array}$ & Revestida en piedra & Balsa para riego & 415 & 10 \\
\hline Venta de Ossete & F & Valle & $\begin{array}{l}\text { Qanat con } \\
\text { lumbreras }\end{array}$ & Revestida en piedra & Balsa para riego & 1500 & 3 \\
\hline Casa Robles & F & Terraza fluvial & $\begin{array}{l}\text { Qanat con } \\
\text { lumbreras (2 ram) }\end{array}$ & Horadada en tierra & Balsa para riego & 140 & 0,5 \\
\hline Fuente Ordán & $\mathrm{Nf}$ & Terraza fluvial & $\begin{array}{l}\text { Qanat con } \\
\text { lumbreras (2 ram) }\end{array}$ & Horadada en tierra & Balsa para riego & 160 & - \\
\hline San Ricardo & $\mathrm{Nf}$ & Piedemonte & $\begin{array}{l}\text { Qanat con } \\
\text { lumbreras }\end{array}$ & Revestida en piedra & Balsa para riego & 900 & - \\
\hline $\begin{array}{l}\text { Ojos de } \\
\text { Luchena }\end{array}$ & $\mathrm{F}$ & $\begin{array}{l}\text { Lecho fluvial } \\
\text { de rambla }\end{array}$ & $\begin{array}{l}\text { Cimbra con } \\
\text { lumbreras }\end{array}$ & Revestida en piedra & Desagua en cauce & 235 & 317 \\
\hline Torralba & $\mathrm{Nf}$ & Terraza fluvial & Cimbra o mina & Labrada en roca & $\begin{array}{l}\text { Depósitos de } \\
\text { decantación y balsa } \\
\text { para riego }\end{array}$ & 138 & - \\
\hline Río Turrilla & $\mathrm{Nf}$ & Terraza fluvial & $\begin{array}{l}\text { Zanja con } \\
\text { lumbreras (4 ram) }\end{array}$ & Horadada en tierra & $\begin{array}{l}\text { Molinos hidráulicos } \\
\text { y balsas para riego }\end{array}$ & 3315 & - \\
\hline $\begin{array}{l}\text { Fuente de la } \\
\text { Mina }\end{array}$ & F & Piedemonte & $\begin{array}{l}\text { Qanat con } \\
\text { lumbreras }\end{array}$ & Horadada en tierra & Balsa para riego & 60 & 11 \\
\hline Fuente de Coy & F & Piedemonte & Mina & Revestido en piedra & $\begin{array}{l}\text { Piscina para baño y } \\
\text { balsa de riego }\end{array}$ & - & 8 \\
\hline
\end{tabular}

Elaboración propia

Figura 5. Brocales de las lumbreras, recientemente restauradas, en la galería de captación de la Finca de Ossete

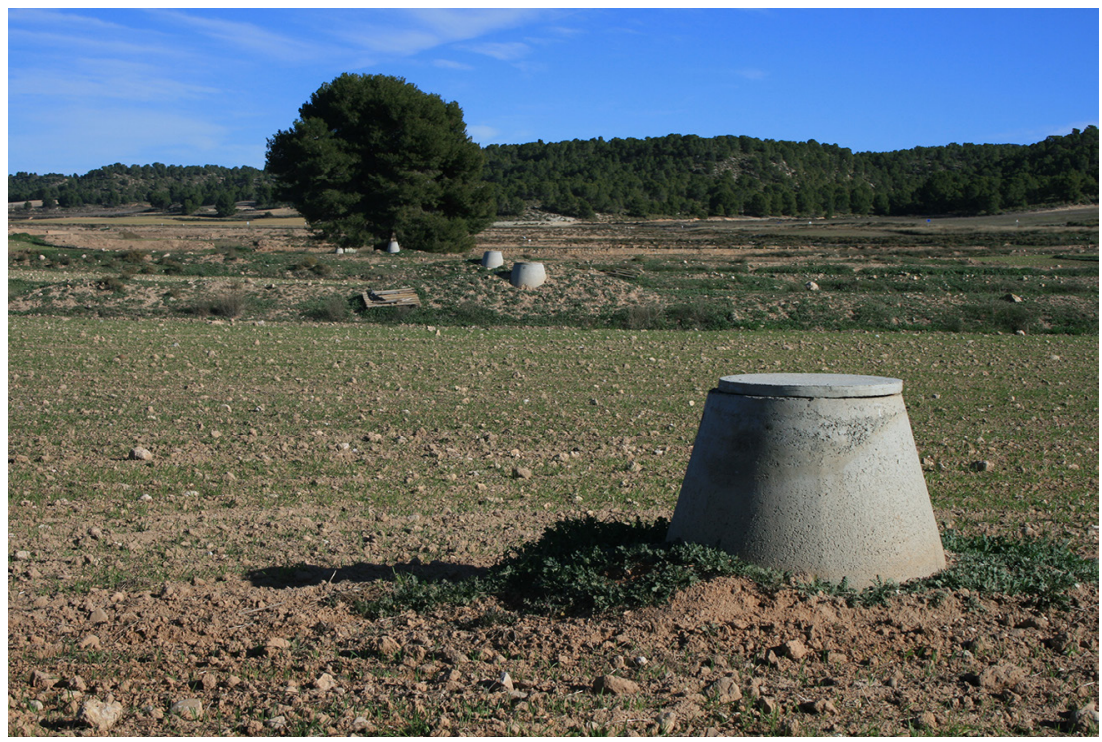

Fotografía del autor 
En función de la localización de estos sistemas y la información hidrogeológica disponible (IGME) (Figura 6), podemos comprobar que los sistemas que mayores caudales han presentado, y presentan, se han construido en zonas de contacto entre materiales permeables e impermeables. Así, Ojos de Luchena constituye la salida natural del acuífero Pericay-Luchena. Por su parte, las galerías de Zarzadilla de Totana y Avilés parecen ser los puntos de salida del acuífero de Zarzadilla; el primero en la cara sur de la sierra de Burete; el segundo, en la cara norte de este relieve bajo la rambla del Cargador. No obstante, en este último caso no estamos seguros de que se trate de un sistema de captación de las aguas del acuífero, sino más bien de filtración de las corrientes subálveas de esta pequeña red hidrográfica.

Figura 6. Principales acuíferos y sistemas de galerías drenantes en el campo alto de Lorca

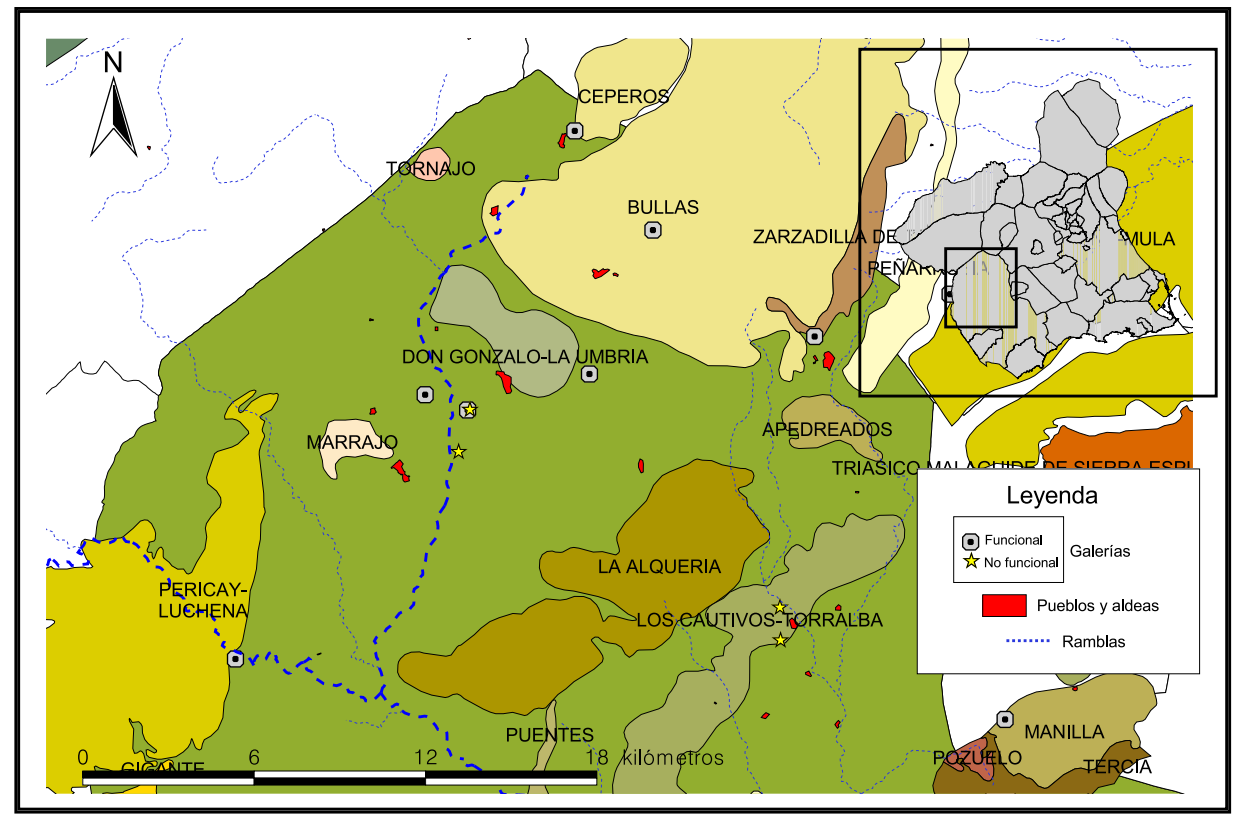

Fuente: Trabajo de campo e información del IGME. Elaboración propia

También constituye un punto de surgencia la galería de San Ricardo, en este caso de una unidad más pequeña como es Los Cautivos-Torralba, aunque en la actualidad se encuentra sin uso. Esos tres sistemas, junto al de Torralba, se localizan al pie de importantes relieves calizos, lugares donde se recoge algo más de precipitación con relación al interior de la cuenca. En el caso de Ojos de Luchena y San Ricardo, aun estando en lechos fluviales, están flanqueados por montañas de cierta vigorosidad, que llegan hasta casi 1.500 metros de altitud. La fuente de La Mina, según un informe de Confederación Hidrográfica del Segura, constituye el único punto de surgencia del acuífero Mingrano-El Rincón; un acuífero relativamente pequeño, de $8,5 \mathrm{~km}^{2}$ y un área de captación permeable de $4,2 \mathrm{~km}^{2}$. (CHS). El resto de sistemas se dan en zonas aluviales, aprovechando igualmente las aguas subálveas de valles y terrazas fluviales o por medio de la captación de pequeños acuíferos colgados. De ahí que, históricamente, sus caudales hayan sido claramente inferiores, usados sobre todo para un consumo local.

\subsection{Los sistemas drenantes de uso local}

La mayor parte de los sistemas inventariados en las pedanías altas de Lorca han servido para abastecimiento local, tanto de personas como de ganado, así como para la puesta en marcha y conservación de un regadío tradicional, desarrollado en torno a los núcleos de población. No obstante, cada ingenio de galería drenante o con lumbreras presenta ciertas singularidades en cuanto a su uso y morfología.

Los ejemplos de Fuente Ordán, San Ricardo y barranco o rambla del Madroño (Torralba) no están en uso en la actualidad. La extracción de aguas subterráneas en sus inmediaciones, por medio de sondeos verticales para la puesta en cultivo de amplias extensiones de tierra durante los años 80 y 90 del siglo XX, ha ocasionado el abandono de estos complejos. En el primer caso, el sistema estaba compuesto por dos galerías de captación horadas en la tierra y varias lumbreras. Las aguas de ambas minas se recogían en una balsa para riego $\mathrm{y}$, aunque no tenemos datos al respecto, no parece ser una obra anterior al siglo XX. 
Por su parte, los caudales subálveos del barranco del Madroño, conocido como aprovechamiento de Torralba, han sido utilizados desde la antigüedad. En el lugar se construyó una galería excavada en roca que captaba y desviaba las aguas de este entorno, y que se conectaría presumiblemente con una villa romana. Por medio del análisis de campo y del trabajo realizado por Gris, Solís y Gris (2002) se constata la presencia de una larga conducción a cielo abierto, horadada en la roca, con varias piscinas de almacenamiento y decantación, que servían para traer las aguas del barranco. El estado de conservación de este tramo es bastante deficitario debido a su abandono, así como por diversas actuaciones realizadas para acondicionar regadíos intensivos. El inicio del sistema, sin embargo, en mejor estado de conservación, estaba configurado por un túnel con "una longitud de 138 metros, contando con un total de cuatro pozos de aireación y dos salidas en rampa, que se usarían para la limpieza y extracción de los sedimentos acumulados en la canalización" (Gris et al., 2002, p. 181). Como señalan estos investigadores, la configuración de un acuífero local, denominado de Torralba, que presenta el juego de materiales margosos infrayacentes y calizas permeables, y que emergen en el barranco del Madroño, justifica que los antiguos pobladores se plantearan la construcción de una galería de captación, con el fin de aprovechar estos recursos que brotarían por su pie, para abastecer a la villa.

En el siglo XX, a escasos dos kilómetros del aprovechamiento de la rambla del Madroño, se construyó otra galería para proveer de agua al poblado que Torralba, núcleo que había crecido en tiempos de la posguerra civil. Este nuevo sistema perforó el acuífero anteriormente descrito, dando agua en la pared final de la mina horizontal, conduciendo los recursos captados a la balsa de San Ricardo o Casa de los Ángeles (Gris et al., 2002), donde todavía puede leerse en su partidor de apertura una señalización de 13 de junio de 1949. La construcción de este complejo requirió el uso de dinamita y la mina se revistió con mampostería para fijar la estructura. Sin embargo, los sondeos verticales de finales de los años 70 condicionaron el funcionamiento de este sistema hasta dejarlo en seco, encontrándose en la actualidad en estado de ruina.

Los sistemas de la rambla del Cargador, al noreste de la población de Avilés (Figura 7), y la Finca de Ossete (Figura 8) se ubican en la misma unidad geomorfológica, aunque en dos ambientes geográficos diferentes. Si el primer ejemplo se sitúa en pleno cauce que desciende de la umbría de la Sierra del Cambrón, el segundo ocupa unos kilómetros más abajo el valle configurado entre esta sierra al este y el Cerro de La Paca, al oeste. Se trata de dos conjuntos de galerías drenantes conservados para usos locales; en Avilés, para el riego tradicional de su huerta. Mientras, en la finca de Ossete, las aguas se suman a las de sondeos profundos que sirven para poner en explotación una finca con carácter intensivo destinada en la actualidad a la producción de olivar. Sendos ejemplos se conservan funcionales, y una muestra de ello son los trabajos de mantenimiento ya comentados.

Figura 7. Bocamina y primer tramo de conducción de las aguas de la galería de Avilés; ejemplo de sistema de filtración en el campo alto de Lorca

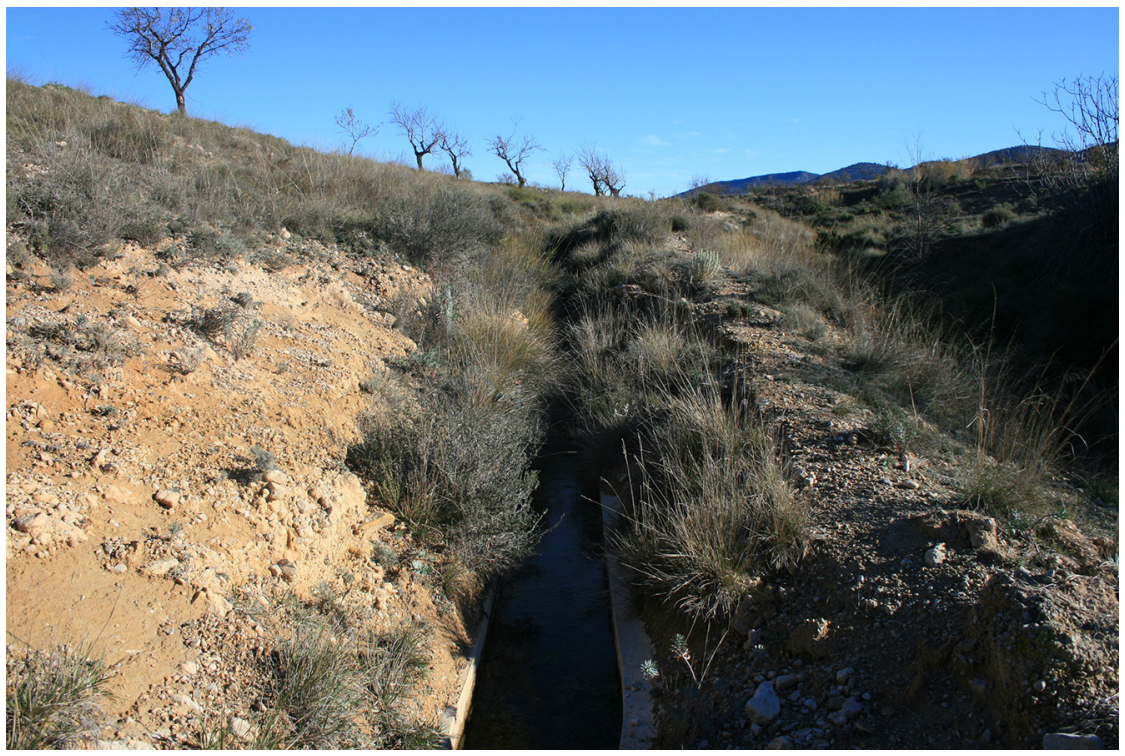

Fotografía del autor 
Respecto al sistema de la finca de Ossete, su importancia ya fue destaca por Elul en 1929. Decenios más tarde, con motivo de la búsqueda de alumbramientos para mitigar las continuas sequías de las pedanías altas de Lorca, el IGME realizó una descripción interior de la misma en 1980. En este documento se reflejaban las características de la galería tradicional de la finca, que cuenta con un recorrido en dirección SW-NE de 1,5 kilómetros a lo largo del valle, destacándose un cambio de sentido SE-NW en su tramo final, hacia el cerro de La Paca; con un caudal de 12 litros por segundo a mediados de los años 70 y que se va a reducir por la sequía hasta los 0,5 litros a comienzos del año 1979. Desconocemos si los trabajos de perforación señalados en este documento se llegaron a realizar; los temores de los geólogos descansaban en la posible salinización del pequeño acuífero La Paca, por lo que acababan sus conclusiones recomendando la vigilancia del su perímetro para evitar la sobreexplotación del mismo, así como evitar el empeoramiento de la calidad de las aguas captadas de forma tradicional.

Figura 8. Balsa de almacenamiento de las aguas de la galería de la finca de Ossete

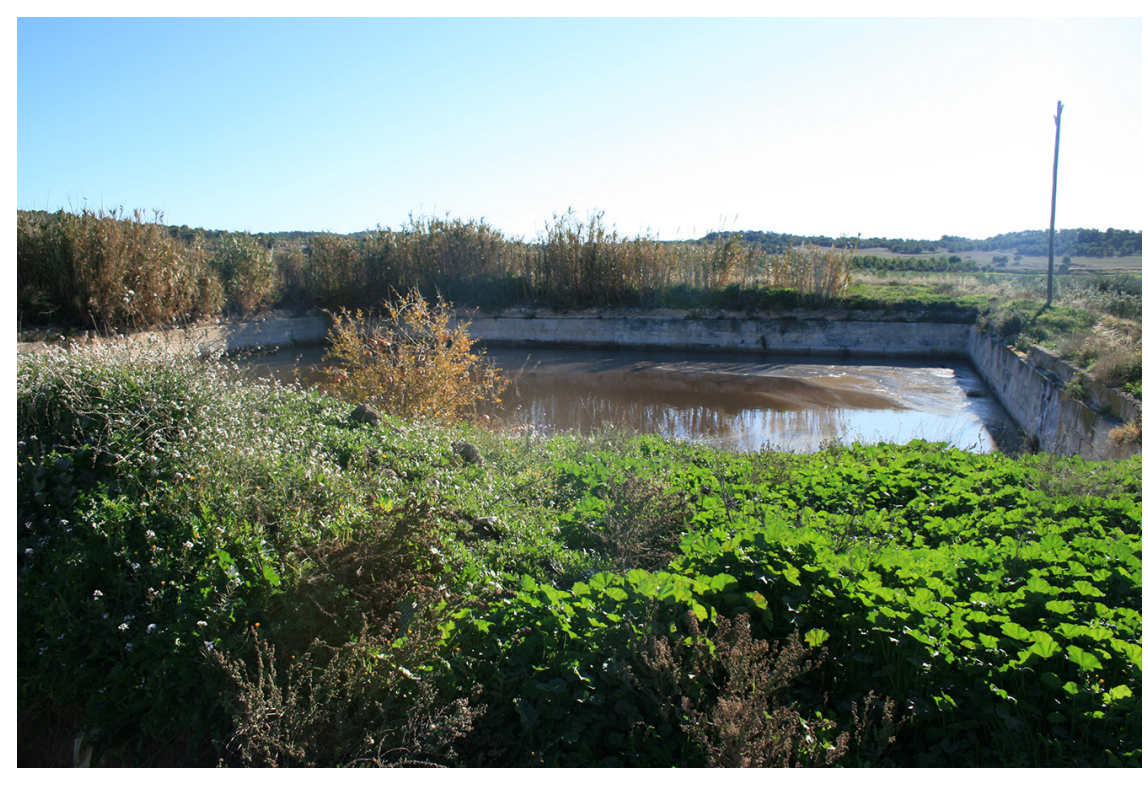

Fotografía del autor

Al inicio del valle del río Turrilla, se localizan los sistemas de la Mina (López, 2015) y Casa Robles, en uso actualmente; y Fuente Ordán y el complejo de Zarcilla de Ramos, sin funcionalidad hoy en día. Se trata de sistemas de captación tradicionales de carácter local, destinados fundamentalmente a regadío tradicional y con la característica compartida de ser sistemas horadados en tierra, sin ningún tipo de revestimiento constructivo. Por su caudal, es de destacar el sistema de La Mina, cuyo origen estaría relacionado con la necesidad de evacuar las aguas que surgían por la extracción de mineral, durante el siglo XIX. En la actualidad, los recursos de este aprovechamiento, uno $250.000 \mathrm{~m}^{3}$ por año, sirven como parte del abasto de la comunidad de regantes del Campo Alto, de 120 comuneros y 435 hectáreas.

El complejo de Zarcilla de Ramos, aunque se encuentra derruido en parte, destaca al estar compuesto por cuatro ramales de galerías, entre ellos el que se disponía en el margen derecho de la rambla de Los Abades, con profundidades que oscilan entre tres y diez metros y que sirvió, en su tiempo, para poner en funcionamiento dos molinos de cubo, el del Agua y el de la Máquina. Además, las aguas, por medio de un entramado de redes de canales a cielo abierto y varias balsas, se utilizaban en las parcelas dispuestas en el fondo del valle del Turrilla; regadío que, en su día, llegó a contar con una conducción proveniente de los Ojos de Luchena. Según los restos superficiales de las conducciones de la galería de la Mina y los de Zarcilla, así como la opinión de algunos vecinos, es probable que todos los recursos se uniesen en un mismo complejo.

Por último, como ejemplo de aprovechamiento local está la fuente de Coy. No se trata de un sistema de galería, sino de una zanja que horada el pie de un cerro calizo hasta convertirse en un pequeño minado, cuyas aguas se han utilizado históricamente para el abastecimiento de la población, disponiendo el caudal en varias fuentes, así como para el regadío. Además, recientemente se ha acondicionado una piscina para baño, que agrada a los vecinos y lugareños en las épocas de estío. 


\subsection{Los sistemas drenantes de uso municipal}

El sistema de Ojos de Luchena se localiza en el cauce de este río, aguas abajo del embalse de Valdeinfierno. En este punto, el río ha creado un cañón que taja la sierra de Pericay de NO a SE, cuyo punto más elevado alcanza los 1.386 metros de altitud en la Morra del Cocón al SO, y 1.235 metros en la pared NE, en la cima de Pericay. Sin embargo, el concepto río puede aplicarse en la actualidad una vez llegados al manantial, ya que anteriormente el cauce permanece completamente seco (Figura 9).

Figura 9. Representación del área donde se localiza el aprovechamiento de Ojos de Luchena

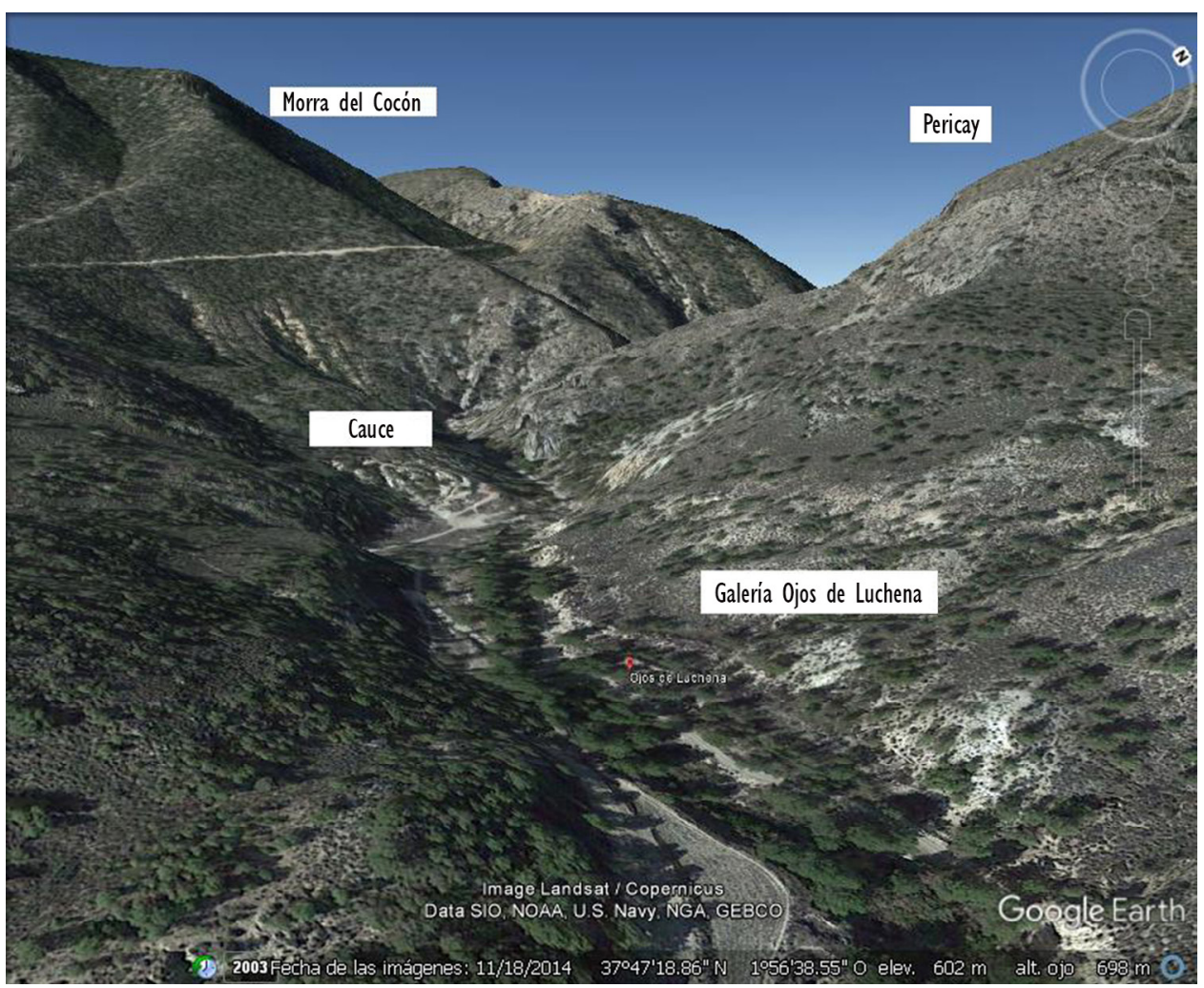

Fuente: Google Earth. Elaboración propia

Se trata de una galería funcional que evacúa las aguas de un amplio acuífero, cuyo proceso constructivo ha sido ampliamente anotado en documentos antiguos. En estos se pone de manifiesto el interés de la población lorquina por disponer de los caudales subterráneos de este territorio. En la actualidad, el sistema presenta la bocamina en el margen izquierdo del cauce, con dos puntos de salida, uno que se continúa mediante canalización por el margen del río y que antaño presentaba un ramal hacia Zarcilla de Ramos. Y otra salida, que vierte las aguas al cauce del río para llevarlas de forma natural hasta el embalse de Puentes.

La galería presenta una forma rectangular, rematada en forma de bóveda. Está revestida y consolidada con cemento enlucido, con una altura en la entrada que alcanza los 2,30 metros, por 1,50 de ancho. Estas dimensiones permiten el tránsito del personal encargado de su conservación y limpieza. El sistema se desarrolla por debajo del cauce, ya que la mina se orienta hacia el margen derecho; sin embargo, información aportada por conocedores de la galería señalan la posibilidad de que otro ramal continúe por la orilla izquierda, presentando una forma de $\mathrm{Y}$, planteamiento que puede coincidir con algunas anotaciones históricas de archivo. El recorrido de la galería principal presenta 6 lumbreras, separadas con distancias que oscilan entre los 30 y 90 metros (Figura 10).

El proceso de construcción y búsqueda de agua en este punto del territorio lorquino puede comprobarse por medio de los datos recogidos por Joaquín Espín Rael, historiador y cronista de la ciudad en la primera mitad del siglo XX. Estos acontecimientos históricos se presentan en formato tabla, donde se muestran los sucesivos intentos de los regantes por aumentar los caudales desde comienzos del siglo XVII (Tabla 2). 
Figura 10. Elementos constructivos que componen la galería de Ojos de Luchena

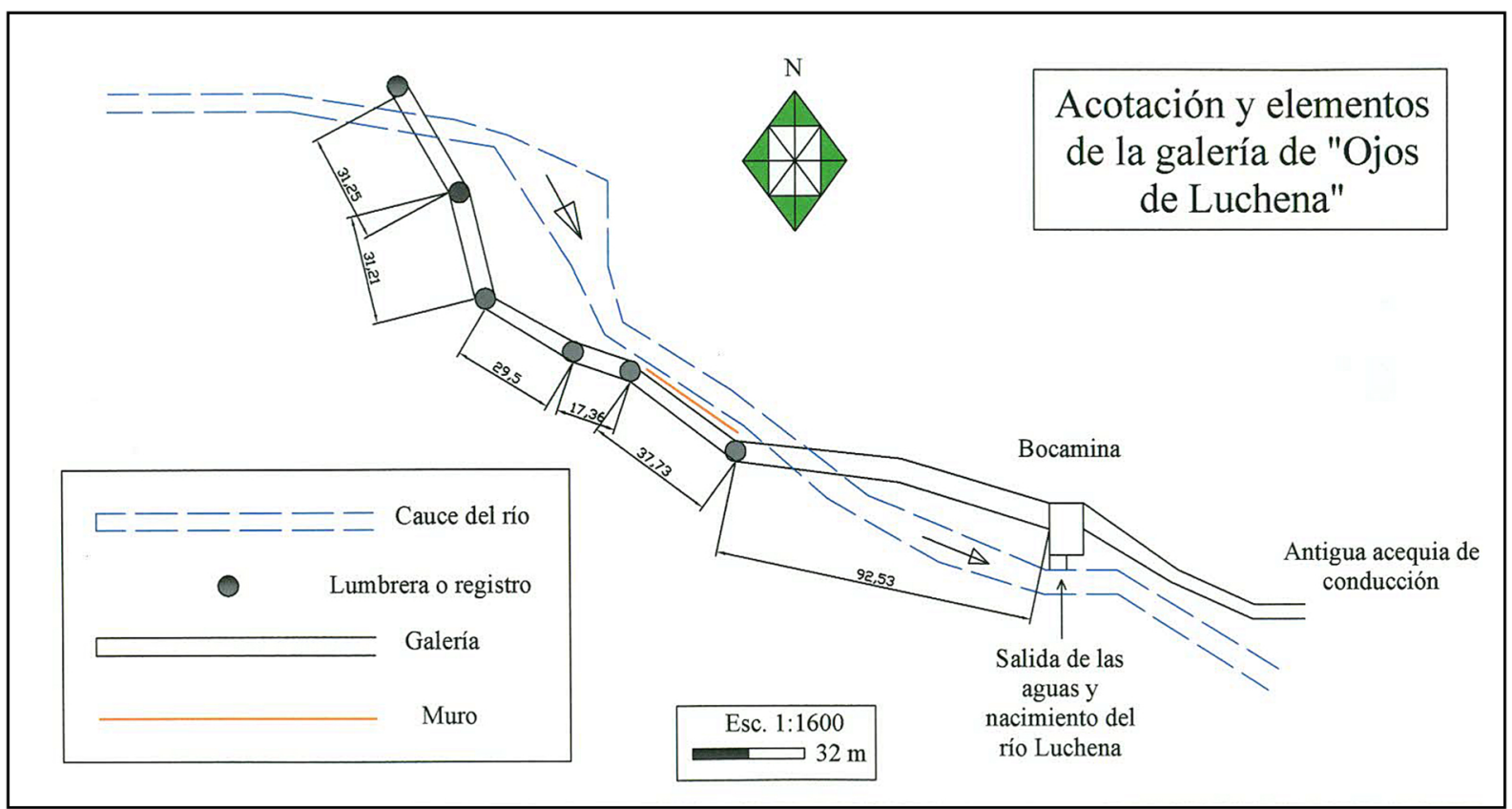

Elaboración propia

Tabla 2. Principales acontecimientos ocurridos en torno al desarrollo del sistema drenante de Ojos de Luchena durante los siglos XVII y XVIII

\begin{tabular}{|c|c|}
\hline Año & Acontecimiento \\
\hline 1603 & Un zahorí informó sobre la posibilidad de aumentar el caudal con excavaciones en la zona de los Ojos \\
\hline 1682 & $\begin{array}{l}\text { Otro zahorí, Fajas, promueve la ampliación de la galería, acometiendo nuevas obras. Después de un accidente, } \\
\text { las obras las dirigiría Melchor de Luzón, que propuso realizar una zanja de } 300 \text { varas de longitud y } 20 \text { palmos } \\
\text { de profundidad, embovedándola para impedir el acceso del río. }\end{array}$ \\
\hline $1686-1688$ & $\begin{array}{l}\text { Continúan los trabajos en Ojos de Luchena, si bien los encargados de las obras Luzón, Fajas y Pelegrín, sobre } \\
\text { todo éste último, consideran que es más apropiado realizar obras en la Fuente del Oro y no en Luchena. }\end{array}$ \\
\hline 1689 & $\begin{array}{l}\text { Se practicaron nuevos aforos solicitados por la Junta de Comercio, donde se obtuvieron } 29 \text { hilas. Los cabildos } \\
\text { del Concejo y Colegial consideraron que los trabajos eran infructuosos ya que no se conseguía aumentar el } \\
\text { caudal. Sin embargo, la Junta determinó que siguieran los trabajos dirigidos por Pelegrín, a lo que este se opuso, } \\
\text { "harto de las piojerías de aquí". }\end{array}$ \\
\hline 1690 & $\begin{array}{l}\text { Varios vecinos informan del aumento de dos hilas en el manantial. La Junta manda construir un canal cubierto } \\
\text { desde el Ojo de la Capilla, terminado el } 25 \text { de septiembre de } 1691 \text {, con una longitud de } 44 \text { varas (unos } \\
36 \text { metros), } 6 \text { palmos de ancho y } 10 \text { de altura; obras que no registraron aumento alguno. De } 1686 \text { a } 1691 \text { se } \\
\text { contabilizó un gasto de } 99.923 \text { reales. }\end{array}$ \\
\hline 1730 & $\begin{array}{l}\text { Solicitud de varios labradores de actuar en Luchena sin afectar a los manantiales. Obras donde se utilizaron } \\
\text { barrenos en una pared de una peña que daba menos de una hila. En este año, eclesiásticos del municipio } \\
\text { proponer continuar realizando labores de explotación, celebrando misas y novenarios en el Calvario y San } \\
\text { Francisco, para concebir el éxito de las mismas. El ingeniero Pedro Coyzevox informó de la necesidad de abrir } \\
\text { una zanja de } 1.200 \text { varas cúbicas, con un coste aproximado de } 50.000 \text { reales. }\end{array}$ \\
\hline 1731 & $\begin{array}{l}\text { Dan comienzo las obras planteadas por Coyzevox, además de terminarse los trabajos de nivelación de la acequia } \\
\text { de conducción, realizada por Juan de Miras. Los trabajos de la galería estaban a medio construir, hasta el punto } \\
\text { donde se suponía estaban las aguas, pero en septiembre aconteció una gran crecida que anegó y destruyó todo } \\
\text { el conducto, dejándolo inservible. }\end{array}$ \\
\hline 1733 & $\begin{array}{l}\text { Se retoman los esfuerzos por seguir trabajando en la zona. Se intentan recuperar los datos de los aforos de } 1731 \text {, } \\
\text { sin éxito. }\end{array}$ \\
\hline 1737 & $\begin{array}{l}\text { Nuevos informes insisten en reabrir las zanjas realizadas antaño y embovedarlas, con un coste estimado de } \\
15.000 \text { reales. Se proponía limpiar los manantiales y continuar la zanja antigua, además de hacer otra mina en } \\
\text { la margen contraria, así como nuevos ramales en una y otra mina; todo ello con un coste de } 300.000 \text { reales. }\end{array}$ \\
\hline
\end{tabular}




\begin{tabular}{|c|c|}
\hline 1756 & $\begin{array}{l}\text { Condicionados por una acuciante sequía, se proponen nuevos trabajos en Luchena. Chardenoux y García } \\
\text { Campoy proponen nuevos proyectos. Un particular, Patricio Gálvez Borgoños ofreció } 50.000 \text { reales sin intereses. } \\
\text { Muchos vecinos acudieron a trabajar al lugar, donde Espín Rael destaca los disparates y estropicios que estos } \\
\text { hacen sobre la antigua bóveda. }\end{array}$ \\
\hline 1757 & $\begin{array}{l}\text { Nueva autorización a Patricio Gálvez, pero nuevas avenidas ciegan los manantiales y cimbras construidas hasta } \\
\text { el momento, con lo que los trabajos se destinaron a la limpieza de las galerías. }\end{array}$ \\
\hline 1758 & $\begin{array}{l}\text { Por una Real Provisión de } 8 \text { de abril, del Real Concejo de Castilla, se creará una Junta Real de Aguas, encargada } \\
\text { de planificar nuevas obras en Luchena. El ingeniero Juan Antonio García Serón aconsejó no realizar más obras } \\
\text { en el lugar, y sí limpiar el manantial del Ojo Grande, que debía resguardarse con una bóveda. La Real Junta no } \\
\text { estaba de acuerdo con lo señalado por Serón, y se realizaron nuevos aforos: } 43 \text { hilas. }\end{array}$ \\
\hline 1759 & $\begin{array}{l}\text { Los trabajos del año anterior se retomaron en marzo de 1759. Sin embargo, una nueva avenida destruyó todo } \\
\text { lo realizado. Un año después, D. Diego Miguel García señala lo inútil de realizar más trabajos en el lugar, y } \\
\text { recomienda limpiar la bóveda vieja y encauzar las aguas hasta Lorca. Para examinar esta propuesta se mandó } \\
\text { a García Campoy marcar las aguas en varios puntos y se observó que el caudal era superior por encima del } \\
\text { pantano de Puentes que a su llegada a la huerta lorquina. Además, se propuso traer las aguas de Caravaca. }\end{array}$ \\
\hline $\begin{array}{l}1761-1762- \\
1763\end{array}$ & $\begin{array}{l}\text { Se acometen las obras de fábrica propuestas, sobre todo la construcción de un canal para llevar las aguas a Lorca } \\
\text { en } 1759 \text {. }\end{array}$ \\
\hline 1766 & Nuevos trabajos de mantenimiento por la rotura de la bóveda del manantial de Luchena \\
\hline 1768 & $\begin{array}{l}\text { Disolución de la Junta de Aguas, dando cuenta de otra Real Provisión del Consejo de Castilla, debido al gasto } \\
\text { que supuso su actuación, que ascendía a } 228.444 \text { reales (comisario, maestro de obras, oficiales, barreneros, } \\
\text { peones y pólvora). }\end{array}$ \\
\hline 1769 & El ingeniero militar Juan Escofet proyectó nuevas obras en el río, para proteger las pérdidas de agua. \\
\hline 1817 & $\begin{array}{l}\text { Los agricultores crean la Junta de Labradores, con el fin de buscar nuevos caudales. Estos trabajos fueron } \\
\text { realizados por el ingeniero Prat, que aconsejó no seguir con los trabajos. Los labradores recelaron de Prat por } \\
\text { estar influido por la Real Empresa de Aguas, a quienes beneficiaba no aumentar los caudales, ya que el agua se } \\
\text { vendía en subasta pública. La Junta fue suprimida por el Ayuntamiento en } 1820 \text {. }\end{array}$ \\
\hline
\end{tabular}

Fuente: Registros realizados por Juan Espín Rael (AML)

La información histórica de este aprovechamiento, cuyo fondo documental se denomina "Sindicato de Riegos" en el Archivo Municipal de Lorca, también permite comprobar el aforo registrado por este manantial desde finales del siglo XVII (Tabla 3). Estos datos, difundidos por Espín Rael a principios de siglo XX y que han sido posteriormente recogidos por otros investigadores (Rodríguez, 1995; García y Pelegrín, 2002), además, ha posibilitado analizar la influencia de la presa de Valdeinfierno sobre el manantial situado aguas abajo, ya que ésta empezó a construirse en 1785 pero no funcionó hasta 1897, mucho tiempo después de estar en explotación la galería de los Ojos de Luchena que, como hemos visto, hay constancia de afloramientos a finales de la centuria del seiscientos.

Tabla 3. Aforos de Ojos de Luchena desde el siglo XVII hasta finales del XX

\begin{tabular}{|c|c|}
\hline Fecha & Caudales $(\mathbf{l} / \mathbf{s})$ \\
\hline Anterior a 1682 & 286 \\
\hline $01 / 11 / 1688$ & 396 \\
\hline $24 / 03 / 1689$ & 297 \\
\hline $16 / 05 / 1689$ & 319 \\
\hline $22 / 09 / 1758$ & 473 \\
\hline $28 / 08 / 1763$ & 594 \\
\hline $16 / 08 / 1764$ & 660 \\
\hline $01 / 02 / 1866$ & 290 \\
\hline $23 / 01 / 1991$ & 547,71 \\
\hline $24 / 01 / 1992$ & 345,29 \\
\hline $05 / 11 / 1993$ & 413,08 \\
\hline
\end{tabular}

Fuente: Rodríguez (1995) y García y Pelegrín (2002) 
Las continuadas labores de construcción y reconstrucción de la galería, unido a la incesante búsqueda por aumentar los caudales para el regadío de Lorca, determinan la recogida de información sobre los recursos disponibles a lo largo de los siglos XVII, XVIII y XIX. Todos los trabajos realizados contarán con cálculos y toma de datos sobre el resultado de las nuevas prospecciones, para compararlos con la situación anterior. Posteriormente, desde los años 80 del siglo XX en adelante, el aforo de los caudales es realizado por el Instituto Geológico y Minero de España, junto a la Comunidad de Regantes de Lorca.

Como puede observarse, se trata de una de las galerías drenantes de mayor caudal, no solo en el territorio de estudio, sino en todo el sureste de España. Además, los caudales de este aprovechamiento han sido comparados a través de la influencia que pudiera existir por la construcción posterior, unos 3 kilómetros aguas arriba, del embalse de Valdeinfierno. Sin embargo, la galería no ha mostrado signos de haber sufrido variaciones por este motivo a lo largo de estos últimos siglos. Rodríguez (1995, p. 78) destaca que "el agua superficial almacenada en el pantano (...) y la que sale por la fuente sería aproximadamente la misma que la superficial que se infiltraba (...) entre la fuente y el pantano". Por su parte, García y Pelegrín (2002) resaltan que "los datos históricos del caudal de Ojos de Luchena (...) comparándolos con los valores registrados hoy en el manantial, no parecen inferiores aquellos, de épocas pasadas, a los que se registran hoy en la actualidad" (p. 10).

Por su parte, el sistema de Zarzadilla de Totana, como se dijo, se encuentra a unos 500 metros por encima del núcleo de población actual, en el glacis de la elevación de Pedro Ponce, relieve que alcanza los 1.525 metros de altitud. El complejo hidráulico se compone de una captación en forma de galería con 9 lumbreras de aireación, en la actualidad protegidas en su brocal con obra de mampostería y losa de hormigón. El lugar presenta unas condiciones favorables para el acopio de aguas, situación destacada por Elul en 1929. Aunque el reconocimiento interior no es posible a día de hoy, este ingeniero reseñaba la complejidad interior de la galería ya que según describe, en cada base de las lumbreras, existe otra mina transversal que busca aumentar los recursos disponibles de todo el conjunto. De este modo, podemos interpretar que se trata de una trama de galerías ideada por los constructores para captar la mayor cantidad de agua posible (Gómez y López, 2006). Varios lugareños indican que se trata de una mina de pequeñas dimensiones, de difícil tránsito, ya que se tenía que entrar de rodillas para hacer las tareas de limpieza y mantenimiento.

El complejo hidráulico cuenta con un depósito a la salida de la bocamina, desde donde las aguas se distribuyen hacia un lavadero público y una fuente, hasta llegar a una balsa de almacenamiento donde se gestiona el regadío tradicional del pueblo, de apenas 20 hectáreas de extensión, por medio de diversas acequias y pequeños partidores. Así, el agua se utilizaba para el consumo humano, usos lavaderos y para la producción agrícola. No obstante, la bondad de esta captación y la falta de recursos en la capital lorquina despertaron el interés de estos en épocas pasadas.

Si bien las aguas de este sistema han sido bastante inferiores al sistema de Ojos de Luchena, la necesidad de abastecimiento de la capital lorquina durante el siglo XVIII hizo que los regidores y agricultores prestasen interés por disponer de estos recursos. No sin tener problemas con los vecinos de Zarzadilla, así como con el Consejo de Castilla, contrario en un primer momento a realizar obras de conducción debido al costo de la misma y la existencia de fuentes cercanas a la capital, en septiembre de 1768 se encargó un estudio para analizar la implementación de un trasvase que llevase parte del caudal de este manantial a los dominios de Lorca. Según varios informes, entre ellos el de Aguas y Pantanos y el de Asuntos y diligencias de las aguas de los manantiales y Rollo de Zarzadilla, hecha con la oficial presencia, existentes en el Archivo Municipal de Lorca (Leg. 300. S. II. Año 1809 y Leg. 3. 5 de octubre de 1772 respectivamente), bajo el contexto de una secular sequía, se advertía de la generosidad de las aguas de este sistema. Así, un lustro después se empezó a realizar la obra de conducción de las aguas, dirigidas por el ingeniero militar Juan Escofet (que también había participado en la búsqueda de caudales en las pedanías altas), al que posteriormente sustituiría el arquitecto Jerónimo Martínez de Lara. El aprovechamiento de las aguas se repartiría en Lorca a través de 60 fuentes públicas pero, sobre todo, servirían para el abastecimiento de los barrios de San Cristóbal, con 9.000 habitantes en 1776, y Santa Quiteria, donde se dispuso una fuente con cinco caños. Se trata de una infraestructura de 23 kilómetros de longitud, que contaba con varios tramos de acueductos, y que entró en funcionamiento en 1781 con un coste total de 1.300 .000 reales. Además, un edicto del 13 de abril de 1779 emitido por el Real Concejo de la Villa, en previsión de lo cuantioso de esta agua, determinó que las sobrantes de la Cañería de Zarzadilla se destinasen al regadío de la huerta lorquina (Pelegrín, 2006). 
El caudal, no obstante, no ha sido de grandes proporciones. Si a comienzos del siglo XX, los aforos registraban 8 litros por segundo (Elul, 1929), durante el siglo XX apenas se contabilizan 3 litros según la Comisaría de Aguas de la Cuenca del Segura. Estos recursos se distribuyen por medio del depósito situado al comienzo del sistema, donde un partidor separa un tercio para el abasto de la villa, y el resto se sigue llevando a la capital municipal. Aunque algún tramo del acueducto sigue en funcionamiento, se produce mayoritariamente por medio de tuberías. Este escaso caudal, en contrapartida con los esfuerzos realizados pone de manifiesto el gran esfuerzo realizado para captar y conducir recursos suficientes para el abasto de personas y el regadío de la huerta.

\section{Discusión de los resultados}

En este contexto geográfico, caracterizado por ser uno de los más secos de la Región de Murcia, la búsqueda de recursos hídricos bajo el suelo ha sido una necesidad durante siglos, al carecer de cursos de aguas superficiales que posibiliten un abastecimiento continuo; un trabajo considerable si se tienen en cuenta los conocimientos y materiales rudimentarios de los que disponía la sociedad, a diferencia de las posibilidades tecnológicas actuales. Así, se entiende el número de galerías y minas construidas a lo largo de este territorio semiárido, que siguen funcionales en la actualidad, y que corroboran la hipótesis inicial de la investigación. Esta recaía en la existencia de numerosos sistemas drenantes, que condicionan el paisaje tradicional y que han servido para abastecer, durante siglos, a la población y generar espacios regados. A este legado patrimonial se unen un conjunto de construcciones complementarias, también relacionadas con el uso del agua, como lavaderos o molinos, entre otros; un bien indispensable, no solamente para el abastecimiento y el regadío, sino también como recurso energético o salutífero.

La información obtenida a través del trabajo de campo y de archivos históricos demuestra el esfuerzo realizado por la sociedad lorquina a lo largo de los siglos para poder disponer de agua, por medio, entre otros, de sistemas de galerías drenantes. Estas construcciones presentan una serie de elementos comunes, como son un pozo madre o inicial, una mina de conducción, pozos de aireación y una bocamina por donde sale el agua a cielo abierto, o continúa a través de canales de forma subterránea hasta alcanzar alguna alberca o depósito; un sistema repetido en otros espacios de la cuenca mediterránea. En el caso de Ojos de Luchena, una vez que las aguas surgen de la bocamina, se utiliza el cauce del río para llevar el caudal hasta el embalse de Puentes, como parte actual del sistema de las infraestructuras de gestión del regadío de Lorca.

Respecto al primer objetivo de esta investigación, referente a la catalogación tipológica de los aprovechamientos, se ha procedido a categorizar las galerías con lumbreras atendiendo a las investigaciones y metodologías propuestas en otros estudios y por otros autores (Murcia; 1958; Gil y Gómez, 1993; Gómez, 2004a y 2004b; Gómez et al., 2007; Hermosilla, Iranzo, Pérez, Antequera y Pascual; 2004) como se observa en la Tabla 1. Sin embargo, según nuestras evidencias, consideramos que cada sistema responde a unas particularidades geológicas, geográficas y sociohistóricas. Como ha quedado documentado para Ojos de Luchena, diversos acontecimientos (avenidas, derrumbes, intereses sociales, materiales constructivos, etc.) han intervenido hasta llegar a la situación actual que presenta este sistema; uno de los aprovechamientos por galería más importantes de España por su caudal que, aunque oscilante anualmente, presenta una media cercana a los $10 \mathrm{Hm}^{3}$.

Los sistemas descritos se encuentran tanto en áreas de piedemontes y glacis, así como en terrazas y cursos fluviales del tipo rambla (Murcia, 1959; Gil et al., 2007; Hermosilla et al., 2004). Respecto a sus características constructivas, se observan minas excavadas en roca; en tierra donde no se presenta ningún tipo de revestimiento ni protección; y otras, que muestran materiales de mampostería en paredes y techo a lo largo del pozo horizontal, así como en el brocal de las lumbreras. A tenor nuestra investigación y teniendo presente la categorización de este tipo de sistemas, es necesario considerar las singularidades de cada construcción, como reflejaron Barceló (1986), Martí (1989) o Ron (1996). De este modo, las características de cada galería van a depender de las formas del relieve de cada territorio, de la tipología de las áreas de captación (lluvias, cubierta vegetal o roquedo, entre otros), de la profundidad en la que se encuentran o buscan los caudales, de los materiales geológicos a perforar, los medios económicos y materiales con los que poder construir y proteger el sistema, de la distancia del pozo madre o nivel subterráneo de las aguas, del número y características de las lumbreras, entre otros. 
Los intentos por clasificar las diferentes galerías ayudan a comprender los rasgos y elementos que dieron lugar al desarrollo de esta forma de encontrar recursos hídricos, con la presencia de elementos comunes como los señalados, pero con características históricas y espaciales concretas, que las hacen, por lo tanto, únicas y singulares. En relación con los datos obtenidos y la información consultada, no podemos asegurar tampoco que los constructores de estos ingenios tuviesen conocimientos mineros (Goblot, 1979); sino que procedían con la construcción de galerías allí donde existían fuentes superficiales, como método para incrementar los recursos disponibles, o labraban una zanja para extraer por gravedad una captación subterránea. Como ha reflejado Palerm (2004) en su revisión sobre las galerías filtrantes mexicanas, también podemos considerar que en el campo de Lorca existen numerosos ejemplos y variedades tipológicas para alumbrar aguas subterráneas; variantes del qanat, que dependen del tipo de agua, de las características de suelo y las técnicas utilizadas, pero que, en todos los casos, son adaptaciones para captar recursos profundos.

En nuestra área de estudio, el pozo madre no llega a superar los 20 metros de profundidad, por lo que no puede concebirse una sobreexplotación de acuíferos profundos. Una vez fuera, los recursos se disponían para diferentes finalidades, entre ellas, el lavado de ropas y enseres (Figura 11), el abastecimiento de animales e, incluso para la puesta en marcha de industrias tradicionales como molinos. No obstante, la necesidad del abastecimiento humano era la principal finalidad de las aguas captadas en los sistemas de galerías de las pedanías altas de Lorca. Como puso de manifiesto el Concejo de Lorca ante la posibilidad de sobrantes del acueducto de Zarzadilla, las aguas se podrían destinar al regadío, siempre que las necesidades de consumo de la población estuviesen aseguradas.

Figura 11. Pequeño lavadero a cielo abierto, dispuesto en el canal de conducción de las aguas de la galería de Avilés, ejemplo de la diversidad del patrimonio hidráulico de este territorio

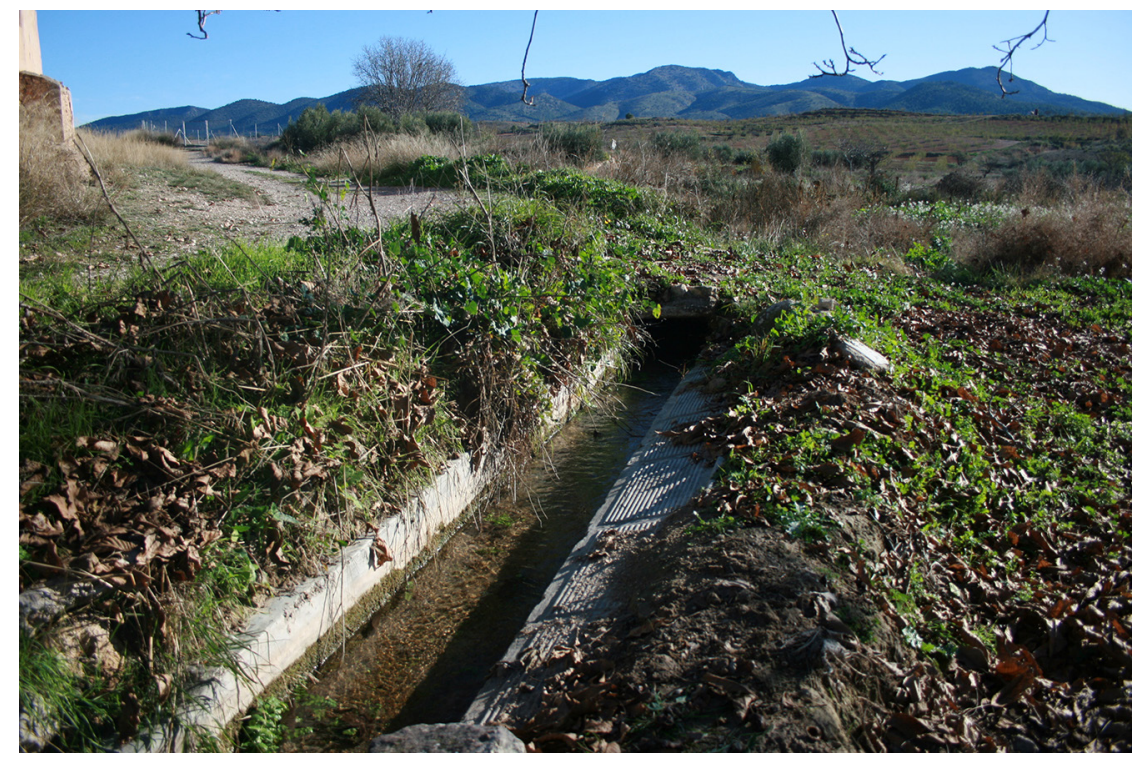

Fotografía del autor

Respecto al segundo y tercer objetivo, que establece la relación entre los aprovechamientos tradicionales del campo alto de Lorca y el desarrollo del poblamiento, podemos indicar varias cuestiones. Respecto al sistema de Ojos de Luchena, este sigue funcional en la actualidad, vertiendo sus aguas al embalse de Puentes, donde se unen a los caudales recogidos en la red del río-rambla de Turrilla. Según la información que aporta la comunidad de regantes de Lorca, las aguas de Luchena presentan un caudal en 2019 de 120 1/seg., lo que equivale en la actualidad al 5\% aproximadamente de los recursos disponibles para el espacio de regadío tradicional (unos 60 millones de $\mathrm{m}^{3}$ en total). Sin embargo, hasta la llegada de las aguas del trasvase Tajo-Segura y la reorganización de los aprovechamientos de la cuenca del Segura, éste constituía el sistema principal y contínuo de recursos para riego.

Por su parte, las aguas de Zarzadilla de Totana llegaban a Lorca por medio de un canal para el consumo de boca, fundamentales durante el siglo XVIII y XIX, pero con un caudal mucho más reducido, que oscilaba entre los 8 y 3 l/seg. Además, parte de las aguas de este aprovechamiento se utilizaba para uso y disfrute de la población de Zarzadilla, tanto para el consumo de boca como lavar o regar; usos que han 
dado lugar a un patrimonio arquitectónico de gran valor (Pelegrín, 2006 y 2010). Hoy, los recursos de este aprovechamiento solo abastecen al núcleo rural.

La singularidad de los aprovechamientos del resto de las galerías de las pedanías altas de Lorca también se observa en los ejemplos de la Mina, los Pozos de la Fuente en Avilés o Venta de Ossete, funcionales desde hace siglos con el fin de alumbrar aguas subsuperficiales, y aprovechados para abastecimiento local de la población y el regadío. De igual modo, el uso tradicional de sus aguas configura espacios regados que no se entienden si no se tiene en cuenta la funcionalidad de los sistemas de galerías drenantes.

Los aportes de los sistemas locales que están en uso se ven complementados en la actualidad por sondeos profundos y el aprovechamiento de aguas residuales. Sin embargo, los recursos subterráneos presentan alta salinidad, otorgando gran valor a la calidad del agua de las galerías, apreciadas por los agricultores locales. Además, éstas nutren pequeños espacios regados que no pertenecen a la comunidad de regantes del Campo Alto, por lo que los sistemas drenantes son los únicos caudales de los que disponen algunos regadíos, como Pozos de la Fuente.

Hoy, la importancia de los sistemas drenantes respecto al aporte de caudal es inferior al de antaño tanto para abastecimiento como para regadío. La toma de boca se da por medio de la Mancomunidad de Canales del Taibilla. Por su parte, las aguas de las galerías drenantes, de excelente calidad, ayudan a conservar huertas tradicionales, simbolizando parte del patrimonio cultural de este territorio. Sin embargo, los nuevos espacios regados inscritos en la comunidad de regantes del Campo Alto se abastecen, además, de algunos sondeos profundos y de los recursos regenerados de la estación depuradora de aguas residuales del río Turrilla; un volumen total disponible que asciende a $459.375 \mathrm{~m}^{3} /$ año para abastecer a 435 Has (CARM, 2018).

\section{Conclusiones}

Entre las particularidades del funcionamiento de estos sistemas históricos está su carácter sostenible, que revierte, a su vez, en el uso integral de los caudales captados. La técnica de la galería horizontal no rompe el equilibrio hídrico de los caudales subterráneos. Debido a la importancia que presentan en la actualidad estos aprovechamientos para el abastecimiento de las pedanías altas de Lorca, muchos intentos por acometer nuevas obras, sobre todo, desde los años 80 del siglo XX en adelante, han encontrado la oposición de la población local, como en Venta de Ossete o Avilés, debido a la afectación que los pozos subterráneos pueden ejercer sobre los sistemas tradicionales, dejándolos en seco y abocándolos a su deterioro.

La historia y las características espaciales del poblamiento del campo alto de Lorca están determinado, en gran medida, por la disposición y aprovechamiento de las aguas de los sistemas drenantes. En la mayor parte de los núcleos de población se encuentran galerías drenantes en sus inmediaciones, infraestructuras esenciales para el abastecimiento de personas y para otros usos como el regadío, la ganadería y la lavandería, además de ayudar a abastecer, caso de galerías de Luchena y Zarzadilla de Totana, al territorio lorquino, junto a otros complejos como las aguas turbias o subálveas de otros puntos del municipio.

El campo alto de Lorca presenta el funcionamiento histórico de una serie de sistemas de captación de aguas, construidos por una población que, secularmente, ha intentado adaptarse a las características áridas y semiáridas de este territorio, de igual modo a lo que sucede en gran parte del mediterráneo español. En el área estudiada podemos confirmar, respecto a la hipótesis de la investigación, que los aprovechamientos hídricos conformados por galerías drenantes posibilitaron fijar la población en este medio rural, sobre todo a partir del siglo XVI y XVII, con el progresivo abandono de los enfrentamientos entre los reinos musulmán y cristiano. De este modo, las surgencias de agua por medio de galerías van a permitir paliar la falta de abastecimiento de personas, de ganados y poner en regadío las huertas locales. Además, la abundancia de algunos de estos sistemas, favorecen el desarrollo de la capital lorquina, por medio de infraestructuras de conducción que sirvieron para traer las aguas alumbradas; construcciones que se suman al patrimonio hidráulico de este territorio, que requiere ser conservado y puesto en valor, ya que sin él no es posible entender la historia y evolución del municipio de Lorca.

\section{Referencias}

Al Karaimeh, S. (2019). Maintaining desert cultivation: Roman, Byzantine, and Early Islamic waterstrategies at Udhruh region, Jordan. Journal of Arid Environments, 166, 108-115. https://doi. org/10.1016/j.jaridenv.2019.03.007 
Antequera, M. (2015). Las galerías drenantes en el sector oriental y suroriental de la Península Ibérica. Identificación, análisis y gestión patrimonial (Tesis doctoral). Universidad de Valencia. https://doi. org/10.4995/ISL2014.2014.216

Antequera, M., Iranzo, E. e Hermosilla, J. (2014). Las galerías drenantes en España: cuantificación y clasificación tipológica de los sistemas horizontales de captación de aguas subterráneas. En Irrigation, Society, Landscape. Tribute to Thomas F. Glick (pp. 1139-1154). Recuperado de http://ocs.editorial.upv. es/index.php/ISL/ISL2014/paper/view/216

Barceló, M. (1983). Qanat(s) a Al-Andalus. Documents d'Analisi Geográfica, 2, 3-22. Recuperado de https://ddd.uab.cat/pub/dag/02121573n2/02121573n2p3.pdf

Barceló, M. (1986). Les aigües cercades: Els qanat(s) de l'illa de Mallorca. Palma de Mallorca: Institut d’Estudis Baleàrics.

Barón, A. y Carbonero, Ma . A. (1987). Las captaciones por gravedad, qanat(s): Situación actual y posibilidades de uso. En IV Simposio de Hidrogeología y Recursos Hidráulicos, Tomo XI (pp. 781-795). Palma de Mallorca: IGME.

Castejón, G. y Canales, G. (2016). El patrimonio hidráulico de la Región de Murcia y la necesidad de su puesta en valor mediante un memorial sobre la cultura del agua. En R. García, F. Alonso, F. Belmonte y D. Moreno (Eds.), XV Coloquio Ibérico de Geografía: Retos y tendencias de la Geografía Ibérica (pp. 458-467). Madrid: Asociación de Geógrafos Españoles.

Comunidad Autónoma de la Región de Murcia (2018). Conexión hidráulica y bombeo solar para la redotación de la comunidad de regantes Campo Alto de Lorca con aguas regeneradas procedentes de la EDAR del río Turrilla. Dirección General de Agua. Recuperado de http://www.carm.es/web/pagi $\underline{\text { na? IDCONTENIDO }=1618 \& \text { IDTIPO }=200 \& \text { RASTRO }=c 709 \$ \mathrm{~m} \& \text { vigente }=1 \text { \& } \mathrm{id}=8 \mathrm{a} 2629246 \mathrm{~d} 6 \mathrm{~b} 328 \mathrm{e}}$ 016d6c79980d0625

Elul, A. (1929-32). Informe y antecedentes sobre el servicio de abastecimiento de agua potable en Lorca. Santomera (Murcia): Legajos s/n. Archivo de la Confederación Hidrográfica del Segura.

Fansa, G., Antequera, M. y Hermosilla, J. (2017). Análisis comparativo de las galerías drenantes tunecinas y del sector oriental y suroriental español. Un modo de captación de aguas subterráneas en la cuenca mediterránea. Boletín de la Asociación de Geógrafos Españoles, 75, 279-317. http://dx.doi.org/10.21138/ bage. 2502

García, F. J. y Pelegrín, M. C. (2002). Reseña histórica e hidrogeológica de la presa de Valdeinfierno y el Manantial de los Ojos de Luchena (Lorca, Murcia). En A. Fernández (Ed), IX Simposio De Hidrogeología, (pp. 677-688), Zaragoza: CNEGP.

Gea, M. (1990). Sistemas de captación y distribución de aguas de probable origen árabe, en Albatera y Crevillente. Revista Sharc-Al-Andalus, 7, 175-194. https://doi.org/10.14198/ShAnd.1990.7.14

Gil, A. (1993). La propiedad de las aguas perennes en el Sureste Ibérico. Alicante: Universidad de Alicante.

Gil, E. (Coord.) (2007). Sistemas locales de recursos propios de agua en la Región de Murcia: Minados y Galerías. Murcia: Colección Usos del agua en el territorio. Universidad de Murcia.

Gil, E. (Coord.) (2009). Paisaje y patrimonio generados por galerías y minados en la Región de Murcia. Murcia: Colección Usos del Agua en el territorio. Universidad de Murcia.

Gil, E. y Gómez, J. Mª (1993). Galerías con lumbreras en el Sureste de España. Papeles de Geografía, 19, 125-145. Recuperado de https://revistas.um.es/geografia/article/view/44271

Gil, E. y Gómez, J. Ma. (Coord.) (2007). Modelos de sostenibilidad en el uso del agua en la Región de Murcia. Murcia: Colección Usos del agua en el territorio. Universidad de Murcia.

Goblot, H. (1979). Les Qanats. Une technique d acqusition de l'eau. Paris-La Haye-New York: Mouton Editeur.

Gómez, J. Ma . (2004a). Aprovechamiento integral del agua en la Rambla de Nogalte (Puerto LumbrerasMurcia). Murcia: Colección Usos del agua en el territorio. Universidad de Murcia.

Gómez, J. Ma . (2004b). Sostenibilidad de usos del agua en el territorio frontera de los antiguos reinos de Granada y Murcia. Papeles de Geografía, 40, 49-66. Recuperado de https://revistas.um.es/geografia/ article/view/44551 
Gómez, J. Mª., Gil, E., Aliaga, I., López, J. A. y Martínez, R. (2007). Las galerías, construcciones para alumbrar agua de freáticos próximos en el Noroeste de la Región de Murcia: minados con espejuelos en Jumilla. Investigaciones Geográficas, 42, 89-107. https://doi.org/10.14198/INGEO2007.42.04

Gómez, J. Ma . y Hervás, R. Mª (Coord.) (2012). Patrimonio hidráulico y cultura del agua en el Mediterráneo. Murcia: Fundación Séneca. Campus Mare Nostrum. Agencia Española de Cooperación Internacional para el Desarrollo.

Gómez, J. Mª y López, J. A. (2006). Galerías con lumbreras en el área central de la Región de Murcia. Papeles de Geografía, 43, 31-59. Recuperado de https://revistas.um.es/geografia/article/view/43551

Gris, L., Solís, L. y Gris, J. (2002). El acueducto romano de Torralba. Caracterización funcional, hidrológica y aspectos socioeconómicos ligados a su explotación. Revista Alberca, 1, 171-209. Recuperado de http://www.amigosdelmuseoarqueologicodelorca.com/alberca/1.php

Hermosilla, J. (Coord.) (2006). Las galerías drenantes del Sureste de la Península Ibérica. Uso tradicional del agua y sostenibilidad en el Mediterráneo español. Madrid: Ministerio de Medio Ambiente.

Hermosilla, J. (Dir.) (2008). Las galerías drenantes en España. Análisis y selección de qanat(s). Madrid: Ministerio de Medio Ambiente.

Hermosilla, J., Antequera, M. e Iranzo, E. (2012). Identificación, análisis, evaluación y puesta en valor de un patrimonio hidráulico singular: las galerías de agua de Túnez. En J. Ma . Gómez y R. Mª Hervás (Coords.), Patrimonio hidráulico y Cultura del agua (pp. 2015-226). Murcia: Fundación Séneca. Campus Mare Nostrum. Agencia Española de Cooperación Internacional para el Desarrollo.

Hermosilla, J. e Iranzo, E. (2014). Claves geográficas para la interpretación del patrimonio hidráulico mediterráneo. A propósito de los regadíos históricos valencianos. Boletín de la Asociación de Geógrafos Españoles, 66, 49-66. https://doi.org/10.21138/bage.1779

Hermosilla, J., Iranzo, E., Pérez, A., Antequera, M. y Pascual, J. A. (2004). Las galerías drenantes de la provincia de Almería. Análisis y clasificación tipológica. Cuadernos de Geografía, 76, 125-154. Recuperado de https://ojs.uv.es/index.php/CGUV/article/view/14414/13189

Hernández, M. y Morales, A. (2013). Los aprovechamientos tradicionales de las aguas de turbias en los piedemontes del sureste de la península ibérica: estado actual en tierras alicantinas. Boletín de la Asociación de Geógrafos, 63, 105-123. http://dx.doi.org/10.21138/bage.1608

Iranzo, E., Antequera, M. y Hermosilla, J. (2010). Identificación, evaluación y puesta en valor de un patrimonio hidráulico singular: Las galerías drenantes de la cuenca del Júcar. Investigaciones Geográficas, 53, 125-143. https://doi.org/10.14198/INGEO2010.53.06

Llamas, M. R. (1976). La utilización de aguas subterráneas en Madrid. De los mayrat musulmanes a los modelos digitales. Estudios Geológicos, 32, 121-139.

López, J. A. (2015). Funcionalidad actual de la Fuente La Mina. Lorca. (Región de Murcia). Papeles de Geografía, 61, 154-168. http://dx.doi.org/10.6018/geografia/2015/208891

López-Camacho, B. (2001). Galerías de captación de agua en la Europa Mediterránea. Revista de Obras Públicas, 3414, 121-126. Recuperado de http://ropdigital.ciccp.es/detalle_articulo. php? registro $=18210 \&$ \&anio $=2001$ \&numero_revista $=3414$

López-Camacho, B., Bustamante, I. e Iglesias, J. A. (2005). El viaje de agua (qanat) de la Fuente Grande de Ocaña (Toledo): Pervivencia de una reliquia hidráulica. Revista de Obras Públicas, 3451, 43-54. Recuperado de http://ropdigital.ciccp.es/detalle_articulo.php?registro=18114\&numero_ $\underline{\text { revista }=3451 \& \text { \&anio }=2005 \text { \&anio_ini }=2000 \& \text { \&anio_fin }=2009}$

Luna, M., García, T. y Luján, M. (2006). Catálogo de bienes inmuebles en el municipio de Lorca. En XVII Jornadas de Patrimonio Histórico (pp. 273-278). Murcia: Consejería de Educación y Cultura.

Madoz, P. (1850). Diccionario Geográfico-Estadístico-Histórico de España y sus posesiones de Ultramar. Madrid: Establecimiento literario-tipográfico de P. Madoz y L. Sagasti.

Martí, R. (1989). Oriente y occidente en las tradiciones hidráulicas medievales. En El agua en zonas áridas: arqueología e historia (I Coloquio de Historia y Medio Físico) (pp. 421-440). Almería: Instituto de Estudios Almerienses. Departamento de Historia.

Martínez, J. y Ruano, P. (1998). Aguas subterráneas. Captación y aprovechamiento. Madrid: Progensa. 
Megdiche-Kharrat, F., Ragala, R. \& Moussa, M. (2019). Promoting a sustainable traditional technique of aquifer water acquisition common to arid lands: A case study of Ghassem Abad Qanat in Yazd Province (Iran). Water Science and Technology: Water Supply, 19(2), 527-535. https://doi.org/10.2166/ ws.2018.098

Ministerio de Industria y Energía (1980). Informe del sondeo de abastecimiento a La Paca (Lorca). Instituto Geológico y Minero de España.

Murcia, A. (1958). Aguas subterráneas. Prospección y alumbramiento para riegos. SERIE I. Manuales técnicos, $n^{\circ} 18$. Publicaciones del Ministerio de Agricultura.

Ortega, J. (2000). Los horizontes de la Geografía. Teoría de la Geografía. Barcelona: Editorial Ariel.

Palerm, J. (2004). Las galerías filtrantes o qanats en México: Introducción y tipología de técnicas. Agricultura, Sociedad y Desarrollo, I(2), 133-145. Recuperado de http://www.scielo.org.mx/scielo. php?script=sci_arttext\&pid=S1870-54722004000200003

Pavón, B (1990). Agua: aljibes, puentes, qanats, acueductos, jardines, ruedas hidráulicas, baños, corachas. Madrid: Consejo Superior de Investigaciones Científicas. (C.S.I.C.).

Pelegrín, M. C. (2006). Obras hidráulicas históricas de Lorca. Revista Alberca, 4, 165-171. Recuperado de http://www.amigosdelmuseoarqueologicodelorca.com/alberca/4.php

Pelegrín, M. C. (2010). El abastecimiento de agua potable a Lorca hace 80 años. Revista Alberca, 8, 181-188. Recuperado de http://www.amigosdelmuseoarqueologicodelorca.com/alberca/8.php

Pérez, Mª T. (2005). Sistemas hidráulicos en el mediterráneo español y el norte de África, 1840-50 / 2000. Mediterráneo e Historia Económica, 7, 57-79.

Pocklington, R. (1988). Toponimia y sistemas de agua en Sharq al-Andalus. En Agua y poblamiento musulmán (pp. 103-114). Benissa.

Rodríguez, T. (1995). Evaluación de reservas y recursos hídricos y normas de explotación generales del acuífero Pericay-Luchena (Murcia). Murcia: Tabala S.L.

Ron, Z. (1996). Sistema de manantiales y terrazas irrigadas en las montañas mediterráneas. En Agricultura y regadio en Al-Andalus. (II Coloquio de Historia y Medio Físico) (pp. 386-408). Almería: Instituto de Estudios Almerienses y Grupo de Investigación Toponimia, Historia y Arqueología del Reino de Granada.

Roth, D y Schütt, B. (2001). Las galerías con lumbreras (qanats): obras maestras de la ingeniería rural amenazados. Revista Velezana, 20, 53-64. Recuperado de https://www.researchgate.net/profile/ Dietmar_Roth/publication/288668737_Las_galerias_con_lumbreras_qanat_Obras_maestras_de_ ingenieria_rural_amenazada/links/5d75696f92851cacdb2bd25b/Las-galerias-con-lumbreras-qanatObras-maestras-de-ingenieria-rural-amenazada.pdf

Trol, C y Braun, C. (1974). El abastecimiento de agua de la ciudad por medio de Qanats a lo largo de la historia (Madrid). GEOGRAPHICA, XVI, 1-4, 235-315.

Vidal, M. J. (1989). Viajes de agua en Madrid. Una perspectiva actual. Los paisajes del agua. Libro jubilar al profesor Antonio López Gómez. Universidad de Valencia-Universidad de Alicante, 265-274.

Voudouris, K., Valipour, M., Kaiafa, A., Yun, X., Kumar, R., Zanier, K., .. \& Angelakis, A. (2019). Evolution of water wells focusing on Balkan and Asian civilizations. Water Science E Technology Water Supply, 19(2), 347-364. https://doi.org/10.2166/ws.2018.114 